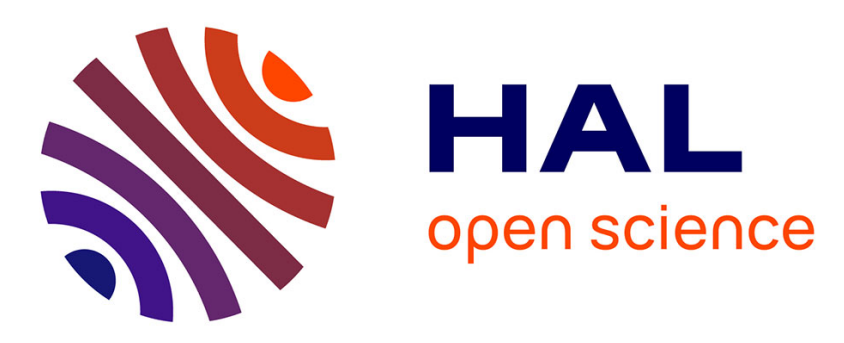

\title{
RAFT Copolymerization of Vinyl Acetate and N-Vinylcaprolactam: Kinetics, Control, Copolymer Composition, and Thermoresponsive Self-Assembly
}

Laura Etchenausia, A.M. Rodrigues, Simon Harrisson, Elise Deniau-Lejeune, M. Save

\section{To cite this version:}

Laura Etchenausia, A.M. Rodrigues, Simon Harrisson, Elise Deniau-Lejeune, M. Save. RAFT Copolymerization of Vinyl Acetate and N-Vinylcaprolactam: Kinetics, Control, Copolymer Composition, and Thermoresponsive Self-Assembly. Macromolecules, 2016, 49 (18), pp.6799-6809. 10.1021/acs.macromol.6b01451. hal-01495405

\section{HAL Id: hal-01495405 \\ https://hal.science/hal-01495405}

Submitted on 2 Dec 2020

HAL is a multi-disciplinary open access archive for the deposit and dissemination of scientific research documents, whether they are published or not. The documents may come from teaching and research institutions in France or abroad, or from public or private research centers.
L'archive ouverte pluridisciplinaire HAL, est destinée au dépôt et à la diffusion de documents scientifiques de niveau recherche, publiés ou non, émanant des établissements d'enseignement et de recherche français ou étrangers, des laboratoires publics ou privés. 


\section{RAFT copolymerization of vinyl acetate and $N$-vinylcaprolactam: kinetics, control, copolymer composition and thermoresponsive self-assembly}

Laura Etchenausia, ${ }^{1}$ Aurélie Malho Rodrigues, ${ }^{1}$ Simon Harrisson, ${ }^{2}$ Elise Deniau-Lejeune, ${ }^{1}$ Maud Save ${ }^{1 *}$

${ }^{1}$ IPREM, Equipe de Physique et Chimie des Polymères, CNRS, University of Pau \& Pays Adour, UMR 5254, ,2 avenue du Président Angot, Pau, F-64053, France

${ }^{2}$ Laboratoire des IMRCP, Université de Toulouse, CNRS UMR 5623, Université Paul Sabatier, 118 route de Narbonne 31062 Toulouse Cedex 9, France

* Corresponding author: maud.save@univ-pau.fr

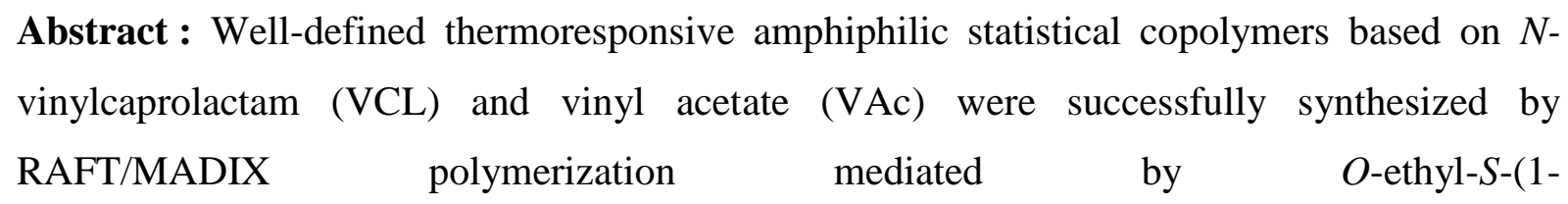
ethoxycarbonyl)ethyldithiocarbonate chain transfer agent at $65^{\circ} \mathrm{C}$. We achieved the synthesis of a series of copolymers with controlled molar masses and low dispersities over a wide range of monomer feed ratios $\left(0<f_{\mathrm{Vac}, 0}<1\right)$. Both conventional linearization methods and a nonlinear least square methods (NLLS) were applied to estimate reliable values of reactivity ratios for VAc and VCL radical polymerization in regards to the disparate values previously reported in the literature. The highest measurement precision was observed for the NLLS method based on the integrated form of the copolymerization equation developed by Skeist. The calculated values of the reactivity ratios $\left(r_{\mathrm{VAc}}=0.33 \pm 0.10\right.$ and $\left.r_{\mathrm{VCL}}=0.29 \pm 0.15\right)$ perfectly fitted the drift in monomer feed ratio versus conversion. The VCL and VAc monomer units are distributed homogeneously along the copolymer chains. Both the cloud point temperatures and glass transition temperatures evolve linearly with the copolymer composition. Analyses of the aqueous solutions of the amphiphilic copolymers by means of dynamic and static light scattering show that $\mathrm{P}(\mathrm{VAc}-\mathrm{co}-\mathrm{VCL})$ copolymers undergo a reversible temperature-induced conformational change between large aggregates $\left(T>T_{\text {cloud point }}\right)$ and either unimers for $F_{\mathrm{VAc}}$ inferior to $0.3\left(N_{\mathrm{agg}}=1, D_{\mathrm{h}} \sim 7 \mathrm{~nm}\right)$ or small aggregates for $F_{\mathrm{VAc}}=0.53\left(N_{\mathrm{agg}}=3, D_{\mathrm{h}} \sim 14 \mathrm{~nm}\right)$. 


\section{INTRODUCTION}

Thermoresponsive polymers are polymers that undergo a conformation phase transition in response to a change of temperature. ${ }^{1,2}$ Among the several well-known thermoresponsive polymers, poly( $N$-vinylcaprolactam) (PVCL) has raised an increasing interest over the last years as reported in recent reviews. ${ }^{3-5}$ This biocompatible polymer with lower critical solution temperature (LCST) in water ranging between $30-40{ }^{\circ} \mathrm{C},{ }^{3,6}$ is attractive for different applications such as delivery systems, ${ }^{4}$ or particle stabilization. ${ }^{7}$ An effective means of tuning the temperature in which the change of PVCL-chain solvation state occurs is to control both the polymer chain length, ${ }^{8-11}$ and the introduction of co-monomers in the polymer chain. ${ }^{10-13}$ Among the different co-monomers that can be used to tune the phase transition temperature of PVCL chains in water, vinyl acetate (VAc) is an attractive co-monomer due to the wide range of applications of poly(vinyl acetate), which is used as a binder for wound dressing, in latex paints, in the paper industry and as a versatile adhesive. ${ }^{14,}{ }^{15}$ Moreover, PVAc is a precursor of poly(vinyl alcohol) which is a biocompatible and biodegradable polymer of interest for biomedical applications, as a stabilizer of colloidal systems or as a superabsorber. ${ }^{15,16}$ During the last decades, controlled radical polymerization (CRP), also recently named reversibledeactivation radical polymerization (RDRP), ${ }^{17}$ has been extensively investigated to precisely control molecular weight, dispersity, architecture and microstructure of a wide range of (co)polymers. ${ }^{18}$ The most developed CRP techniques are nitroxide mediated polymerization $(\mathrm{NMP}),{ }^{19}$ atom transfer radical polymerization (ATRP), ${ }^{20}$ copper(0)-mediated radical polymerization, ${ }^{21,22}$ reversible addition-fragmentation chain transfer (RAFT) ${ }^{23,} 24$ including macromolecular design via the interchange of xanthates (MADIX), ${ }^{25}$ reversible iodine transfer polymerization (RITP) ${ }^{26}$ and organometallic-mediated radical polymerization (OMRP). ${ }^{27}$ Despite the interest of poly(vinyl esters) and poly(vinyl amides) for a range of applications, the controlled radical polymerization of unconjugated monomers has long been recognized as a challenge due to the difficulty in controlling the equilibrium between the unstabilized radical and the dormant species. ${ }^{5,} 14$ In the recent years, improvements in RAFT/MADIX polymerization, ${ }^{9,28-34}$ OMRP, ${ }^{13,35-37}$ RITP $^{38}$ and ATRP, ${ }^{39,} 40$ offered opportunities to control the polymerization of the so-called less activated monomers (LAM) such as vinyl acetate, $\mathrm{N}$ vinylcaprolactam (VCL) or $N$-vinylpyrrolidone (VP). RAFT/MADIX polymerization afforded the possibility to synthesize various LAM-based copolymers such as block copolymers (PVAc$b$-PVCL ${ }^{30}$, PVCL- $b$-PVP $\left.{ }^{41}\right)$ or statistical copolymers (P(VP-stat-VCL) $\left.{ }^{12,}{ }^{42}\right)$. Among controlling the molar mass and dispersity via RDRP, copolymerization kinetics and associated effect on copolymer composition assist in the design of statistical copolymers with suitable 
performances. Indeed, both copolymer composition and monomer distribution of statistical polymer sequences can affect properties such as phase transition temperature, ${ }^{2,12,13}$ blockstatistical copolymer self-assembly, ${ }^{43,44}$ cyclization $^{45}$ and rheological properties of copolymers self-assembled either in water ${ }^{46}$ or in bulk. ${ }^{47,}{ }^{48}$ It requires the most accurate values of the reactivity ratios. However, the discrepancy between the values of reactivity ratios reported in the literature for VAc and VCL copolymerization $\left(r \mathrm{VAc}=0.63\right.$ and $r \mathrm{VCL}=0.31$ (bulk) ${ }^{49,5} r_{\mathrm{VAc}}$ $=0.36$ and $r_{\mathrm{VCL}}=1.06$ (bulk) ${ }^{13,50} r_{\mathrm{VAc}}=0.35$ and $r_{\mathrm{VCL}}=2.5$ (media not reported) ${ }^{51} r_{\mathrm{VAc}}=0.3$ and $r_{\mathrm{VCL}}=2.2$ (ethanol), ${ }^{49} r_{\mathrm{VAc}}=0.3$ and $r_{\mathrm{VCL}}=1.3$ (butanol ${ }^{49}$ provides uncertainty in the monomer sequence along the chain. This might limit the development of more complex materials based on VAc and VCL copolymers. It is thus of interest to explore how effective is RAFT/MADIX polymerization at controlling the copolymerization of VAc and VCL monomers for various initial monomer feed compositions. Special attention is dedicated to the copolymer compositions. Non-linear least square methods and linearization methods are examined to accurately determine the reactivity ratio of VAc and VCL. The influence of the $\mathrm{P}(\mathrm{VAc}-\mathrm{co}-\mathrm{VCL})$ copolymer composition on glass transition temperature, phase transition temperature, and copolymer self-assembly is investigated.

\section{EXPERIMENTAL PART}

\section{Materials}

Vinyl acetate (VAc, Sigma Aldrich, 99\%+) was mixed with inhibitor removers (Sigma Aldrich, $0.1 \mathrm{~g}$ of inhibitor remover for $50 \mathrm{~mL}$ of $\mathrm{VAc}$ ) for 30 minutes prior to be filtered and used for polymerization. $N$-vinylcaprolactam (VCL, Sigma Aldrich, 98\%) was distilled under reduce pressure $(\mathrm{P}=0.05 \mathrm{mmHg})$ in the presence of hydroquinone (Sigma Aldrich, 99\% $\%^{+}$). Azobisisobutyronitrile (AIBN, Sigma Aldrich, 98\%), 1,3,5-trioxane (Sigma Aldrich, $\geq 99 \%$ ), diethyl ether (Sigma Aldrich, $\geq 99.8 \%$ ) were used as received. The $O$-ethyl-S-(1ethoxycarbonyl)ethyldithiocarbonate molecular transfer agent was synthesized according to a previously described procedure ${ }^{52}$ (purity: $93 \%$ ).

\section{General procedure for the synthesis of P(VAc-co-VCL) statistical copolymer}

Polymerizations were performed with a total of $5 \mathrm{~g}$ of monomers, varying the initial molar fraction of VAc and VCL from $f_{\mathrm{VAc}, 0}=0$ to 1 . The initial concentration of xanthate agent was ranging from 1.6 to $2.4 \mathrm{~mol} . \mathrm{L}^{-1}$ and the ratio between monomer concentration and xanthate agent concentration ranged between 420 and 460 (Table S.1. in Supporting Information). 
In a typical experiment (Expt 6 in Table 1), xanthate agent $\left(36.5 \mathrm{mg}, 1.10 \times 10^{-4} \mathrm{~mol}\right)$, AIBN $\left(5.4 \mathrm{mg}, 3.30 \times 10^{-5} \mathrm{~mol}\right), \mathrm{VCL}\left(2.00 \mathrm{~g}, 1.44 \times 10^{-2} \mathrm{~mol}\right), 1,3,5$-trioxane $\left(0.887 \mathrm{~g}, 9.86 \times 10^{-3}\right.$ mol) and VAc $\left(3.04 \mathrm{~g}, 3.53 \times 10^{-2} \mathrm{~mol}\right)$ were introduced in a $10 \mathrm{~mL}$ round bottom flask and stirred magnetically. The mixture was degased by nitrogen bubbling during three minutes in an ice bath. The flask was weighed before and after degasing to ensure the absence of VAc evaporation during this step. A sample was withdrawn under nitrogen at time $t=0$. The round bottom flask was placed into an oil bath previously heated to $65^{\circ} \mathrm{C}$. Samples were withdrawn every hour until the reaction was stopped (6 hours) by cooling down in an ice-water bath and introduction of oxygen in the mixture. Individual conversions of monomers were calculated from nuclear magnetic resonance spectra using 1, 3, 5-trioxane as internal standard (equation $1)$.

$x_{\text {mono }}=\frac{\left(I 1 H_{\text {mono. }} / I 1 H_{\text {triox }}\right)_{t}}{\left(I 1 H_{\text {mono. }} / I 1 H_{\text {triox }}\right)_{0}} \quad$ Equation 1

$I_{1 \mathrm{H} \text {,triox }}$ corresponds to the integral of one proton of 1,3,5-trioxane $(5.1 \mathrm{ppm}, 6 \mathrm{H})$ used as internal standard and $I_{1 \mathrm{H} \text {,mono }}$ corresponds to either the integral of the proton of VCL monomer at 3.6 $\operatorname{ppm}\left(I_{1 \mathrm{H}, \mathrm{VCL}}, 2 \mathrm{H}\right)$ or VAc monomer at 7.1-7.4 ppm $\left(I_{1 \mathrm{H}, \mathrm{VAc}}=I_{7.1-7.4 \mathrm{ppm}}-I_{1 \mathrm{H}, \mathrm{VCL}} / 2\right)\left(\mathrm{see}^{1} \mathrm{H}\right.$ NMR spectrum of a crude sample in Figure S.1 in Supporting Information).

The final overall molar and weight conversions (respectively named $X_{\mathrm{m}}$ and $X_{\mathrm{w}}$ ) were calculated from the monomer individual conversions ( $x_{\text {mono, }}$ equation 1 ) according to equation 2 and equation 3 ( $n_{0}$ and $m_{0}$ are respectively the initial number of moles and the initial mass of each monomer).

$$
\begin{array}{ll}
X_{m}=\frac{x_{\mathrm{VAc}} * n_{0, \mathrm{VAc}}+x_{\mathrm{VCL}} * n_{0, \mathrm{VCL}}}{n_{0, \mathrm{VAc}}+n_{0, \mathrm{VCL}}} & \text { Equation } 2 \\
X_{w}=\frac{x_{\mathrm{VAc}} * m_{0, \mathrm{VAc}}+x_{\mathrm{VCL}} * m_{0, \mathrm{VCL}}}{m_{0, \mathrm{VAc}}+m_{0, \mathrm{VCL}}} & \text { Equation } 3
\end{array}
$$

The molar fraction of the VAc monomer incorporated into the copolymer $\left(F_{\mathrm{VAc}}\right)$ was calculated from the monomer individual conversion ( $x_{\mathrm{VAc}}$, equation 1$)$ and the initial number of moles of monomers ( $n_{0, \mathrm{VAc}}$ and $\left.n_{0, \mathrm{VCL}}\right)$, according to equation 4 .

$F_{\mathrm{VAc}}=\frac{x_{\mathrm{VAc}} * n_{0, \mathrm{VAc}}}{x_{\mathrm{VAc}} * n_{0, \mathrm{VAc}}+x_{\mathrm{VCL}} * n_{0, \mathrm{VCL}}} \quad$ Equation 4

The weight fraction of VAc in the copolymer $\left(w_{\mathrm{VAc}}\right)$ was obtained from equation 5 , considering the molar fraction of the monomers in the copolymer $\left(F_{\text {mono, }}\right.$, equation 4$)$ and the molar masses of each monomer $\left(M_{\mathrm{VCL}}=139 \mathrm{~g} \cdot \mathrm{mol}^{-1}\right.$ and $\left.M_{\mathrm{VAc}}=86 \mathrm{~g} \cdot \mathrm{mol}^{-1}\right)$. 
$w_{\mathrm{VAc}}=\frac{F_{\mathrm{VAc}} * M_{\mathrm{VAc}}}{F_{\mathrm{VAc}} * M_{\mathrm{VAc}}+F_{\mathrm{VCL}} * M_{\mathrm{VCL}}} \quad$ Equation 5

\section{Characterization method}

Nuclear Magnetic Resonance (NMR) spectroscopy. NMR spectra were recorded using a Bruker $400 \mathrm{MHz}$ spectrometer at $25{ }^{\circ} \mathrm{C} .{ }^{1} \mathrm{H}$ measurements were performed at frequencies of $400 \mathrm{MHz}$ and ${ }^{13} \mathrm{C}$ measurements at $100 \mathrm{MHz}$. Deuterated dimethyl sulfoxide DMSO- $d_{6}$ and deuterated chloroform $\mathrm{CDCl}_{3}$ were used as solvents for respectively the crude and precipitated polymers.

Dynamic Light Scattering (DLS). The measurements of the hydrodynamic diameter $D_{\mathrm{h}}$ as a function of the temperature for the $\mathrm{P}(\mathrm{VAc}-\mathrm{co}$-VCL) copolymers dispersed in deionized water at 5 g.L $\mathrm{L}^{-1}$, were carried out on a Nano-ZS, Model ZEN3600 (Malvern, UK) zetasizer at an angle of $173^{\circ}$. A He-Ne $4.0 \mathrm{~mW}$ power laser was used, operating at a wavelength of $633 \mathrm{~nm}$. For evaluation of the data, the DTS (Nano) program was used. The hydrodynamic diameters were calculated from the diffusion coefficient using the Stokes-Einstein equation $D=\frac{k_{\mathrm{B}} T}{3 \pi \eta D_{h}}$ where $T$ is absolute temperature, $\eta$ the viscosity of the solvent, $k_{\mathrm{B}}$ the Boltzmann constant and $D$ is the diffusion coefficient. The hydrodynamic diameters of the the P(VAc-co-VCL) copolymers were also measured accurately using the a ALV setup (Langen, Germany). The values of $D_{\mathrm{h}}$ below the cloud point were calculated from the diffusion coefficient using the Stokes-Einstein equation and was extrapolated to zero concentration and zero-q values.

Static Light Scattering (SLS). Light Scattering measurements were performed on a ALV setup (Langen, Germany), consisted of a $22 \mathrm{~mW} \mathrm{He}-\mathrm{Ne}$ laser, operating at a wavelength of $\lambda=632.8$ nm, an ALV CGS/8F goniometer, an ALV High QE APD detector, and an ALV 5000/EPP multibit, multiautocorrelator. All the measurements were carried out at temperature below the cloud point, for scattering angles, $\theta$, ranging from $30^{\circ}$ to $150^{\circ}$. For $\mathrm{P}(\mathrm{VAc}-\mathrm{co}$-VCL) copolymers with $F_{\mathrm{VAc}}$ inferior to 0.3 , the measurements were performed at polymer concentrations ranging between 1 g.L $\mathrm{L}^{-1}$ and $20 \mathrm{~g} . \mathrm{L}^{-1}$ while for the P(VAc-co-VCL) copolymer with $F_{\mathrm{VAc}}$ of 0.53 , the temperature of measurement was set at $10^{\circ} \mathrm{C}$ at polymer concentrations range of $1-4 \mathrm{~g} . \mathrm{L}^{-1}$. The weight average molar mass of the scatterers $\left(M_{\mathrm{w}}\right)$ was determined using the Zimm equation (equation 6). The average scattered intensity of the sample ( $\left.I_{\text {sample }}\right)$ is measured in relation to the average scattered intensity of the solvent $\left(I_{\text {solvent }}\right)$ and a standard $\left(I_{\text {standard }}\right)$. The Rayleigh ratio $\left(R_{\theta}\right)$ of the sample, which corresponds to the normalized contribution of the sample to the 
scattering intensity, is then determined based on the known Rayleigh ratio of the standard $\left(R_{\theta, \text { standard}}\right.$, here we used toluene with $\left.R_{\theta, \text { Toluene }}=2.79 \times 10^{-5} \mathrm{~cm}^{-1}\right)$, equation 7. K.c/ $R_{\theta}$ can then be determined using equations 6 to 9 , taking into account the wavelength of the laser $(\lambda)$, the refractive index of the standard ( $\left.n_{\text {standard }}\right)$, the refractive index increment $(d n / d c)$ of the sample and Avogadro's number $\left(N_{\mathrm{A}}\right)$.

$\frac{K . c}{R_{\theta}}=\frac{q^{2} R_{g}^{2}}{3 M_{w}}+\frac{1}{M_{w}}+2 A_{2} C \quad$ Equation 6

$R_{\theta}=\frac{I_{\text {sample }}-I_{\text {solvent }}}{I_{\text {standard }}} R_{\theta, \text { standard }}$ Equation 7

$K=\frac{4 \pi^{2} n_{\text {standard }}^{2}(d n / d c)^{2}}{N_{A} \lambda^{4}}$ Equation 8

$q=\frac{4 \pi n_{\text {solvent }}}{\lambda} \sin \frac{\theta}{2}$ Equation 9

For all of the samples, the resulting distribution of relaxation times obtained via DLS was bimodal. To account for the presence of the larger aggregates in the SLS experiments, the relative scattered intensity contributions from fast and slow mode of relaxation were determined from the DLS data, which allowed for the calculation of the Rayleigh ratio for the fast mode only $\left(R_{\theta, \text { fast }}\right) .{ }^{53-55}$

$R_{\theta, \text { fast }}=A_{\text {fast }}(\theta) \frac{I_{\text {sample }}(\theta)-I_{\text {solvent }}(\theta)}{I_{\text {standard }}(\theta)} R_{\theta, \text { standard }}$ Equation 10

$A_{\text {fast }}(\theta)$ is the scattered intensity contribution from the fast mode of relaxation at a given scattering angle determined by DLS, $I_{\text {sample }}, I_{\text {solvent }}$, and $I_{\text {standard }}$ are the scattered intensities at

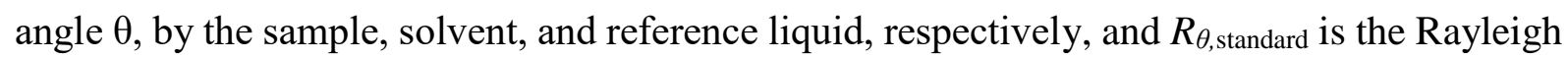
ratio for the toluene used as the standard. The $K . c / R_{\theta \text {,fast }}$ values were averaged across the different q-values and plotted versus concentration to determine the absolute weight-average molar mass $\left(M_{\mathrm{w}, \text { aggregate }}\right.$ (Figure S.2, Supporting Information). The aggregation number was calculated as follows: $N_{\mathrm{agg}}=M_{\mathrm{w}, \text { aggregate }} / M_{\mathrm{w}, \text { polymer, with }} M_{\mathrm{w}, \text { polymer }}$ corresponding to $M_{\mathrm{w}}$ of the copolymer measured by SEC in THF from MALLS detector.

The specific refractive index increment values $(d n / d c)$ of the aqueous solutions of copolymers were determined at $20^{\circ} \mathrm{C}$ with a T-rEX (Wyatt) differential refractometer, operating at a wavelength of $\lambda=632 \mathrm{~nm}$, at concentration ranging form 0.2 to $1 \mathrm{~g} . \mathrm{L}^{-1}$. The following values were measured: $d n / d c=0.177 \pm 0.001 \mathrm{~mL} \cdot \mathrm{g}^{-1}\left(F_{\mathrm{VAc}}=0.28\right), d n / d c=0.171 \pm 0.005 \mathrm{~mL} \cdot \mathrm{g}^{-1}$ $\left(F_{\mathrm{VAc}}=0.19\right)$ and $d n / d c=0.163 \pm 0.008 \mathrm{~mL} \cdot \mathrm{g}^{-1}(\mathrm{PVCL})$. According to these values, the $d n / d c$ 
of the copolymer with $F_{\mathrm{VAc}}=0.53$ was extrapolated at $0.186 \mathrm{~mL} \cdot \mathrm{g}^{-1}$ (Figure S.3, Supporting Information).

\section{Size Exclusion Chromatography (SEC).}

The SEC system operates in THF, at $30^{\circ} \mathrm{C}$ (flow rate: $1 \mathrm{~mL} \cdot \mathrm{min}^{-1}$ ). The SEC apparatus is equipped with a Viscotek VE 1122 automatic injector, a set of shodex columns (KF 801, KF 8025, KF 804 et KF 806 from Waters) working in series, a Wyatt Heleos II Multi Angle Laser Light Scaterring detector (MALLS, 18 angles, $\lambda_{0}=664.4 \mathrm{~nm}$ ), a refractive index (RI) detector Viscotek VE 3580 and a Viscotek VE 3210 UV-visible detector. Toluene was used as flow marker. All (co)polymer samples were prepared at 5 g.L $\mathrm{L}^{-1}$ concentrations. The number-average molar mass $\left(M_{\mathrm{n}}\right)$ and molar mass distribution $(\bigoplus)$ were obtained from MALLS data using the $M_{\mathrm{i}}$ value of each slice of the chromatogram (see equation 6 at zero concentration). The experimental $M_{\mathrm{n}}$ were compared to the theoretical number average molar masses of the copolymers calculated from equation 11.

$M_{\mathrm{n}, \text { theo. }}=M_{\text {Xanthate }}+X_{w} \frac{\left(m_{0, \mathrm{VAc}}+m_{0, \mathrm{VCL}}\right) / V_{\text {Total }}}{\left([\text { Xanthate }]_{0}+0.6 *[\operatorname{AIBN}]_{0} *\left(1-e^{-k_{\mathrm{d}} * t}\right)\right)} \quad$ Equation 11

Where $M_{\text {Xanthate }}$ corresponds to the molar mass of the molecular xanthate agent $\left(M_{\text {Xanthate }}=222\right.$ g.mol $\left.{ }^{-1}\right), X_{\mathrm{w}}$ is the final overall weight conversion (see equation 3), $k_{\mathrm{d}}$ is the AIBN dissociation constant into dimethylformamide at $60^{\circ} \mathrm{C}\left(k_{\mathrm{d}}=6.45 \times 10^{-5} \mathrm{~s}^{-1}\right),{ }^{51} t$ corresponds to the polymerization time, $[\text { Xanthate }]_{0}$ and $[\mathrm{AIBN}]_{0}$ are respectively the initial concentrations of the chain-transfer agent and the initiator. $m_{0, \mathrm{VAc}}$ and $m_{0, \mathrm{VCL}}$ are the initial weight of monomers (in $\mathrm{g})$ and $V_{\text {Total }}(\mathrm{L})$ is the initial volume of the reaction mixture.

The refractive index increments $(d n / d c)$ of the $\mathrm{P}(\mathrm{VAc}-c o-\mathrm{VCL})$ copolymers synthesized by bulk copolymerization were determined using equation 12 .

$(d n / d c)_{\text {copo }}=w_{\mathrm{VAc}}\left(\frac{d n}{d c}\right)_{P V A c}+w_{\mathrm{VCL}}\left(\frac{d n}{d c}\right)_{P V C L} \quad$ Equation 12

The values of $d n / d c$ of PVCL and PVAc homopolymers were respectively taken from references ${ }^{9}$ and ${ }^{51}:(d n / d c)_{\mathrm{PVCL}}=0.109 \mathrm{~mL} \cdot \mathrm{g}^{-1}$ and $(d n / d c)_{\mathrm{PVAc}}=0.0582 \mathrm{~mL} \cdot \mathrm{g}^{-1}$. In order to confirm the $d n / d c$ calculation from equation 12 , the $d n / d c$ value was also measured experimentally by SEC via the plot of the RI area of the chromatogram versus the copolymer concentration (see Figure S.4, Supporting Information). The experimental $d n / d c$ value of $\mathrm{P}\left(\mathrm{VAc}_{0.63}-c o-\mathrm{VCL}_{0.37}\right)$ copolymer (expt 6 in Table 1) $\left(d n / d c_{\text {exp. }}=0.084 \mathrm{~mL}^{-\mathrm{g}^{-1}}\right)$ was in good 
agreement with the $d n / d c$ calculated using equation $12\left(d n / d c_{\text {calc. }}=0.082 \mathrm{~mL} \cdot \mathrm{g}^{-1}\right)$. Therefore, for the series of $\mathrm{P}(\mathrm{VAc}-\mathrm{co}-\mathrm{VCL})$ copolymers, $d n / d c$ values were calculated from equation 12 .

Differential Scanning Calorimetry (DSC). DSC measurements were carried out using the Q100 apparatus from TA instruments. Analysis were conducted at a heating rate of $10^{\circ} \mathrm{C} / \mathrm{min}$, under nitrogen gas flow, from $0^{\circ} \mathrm{C}$ to $200^{\circ} \mathrm{C}$. The measurements method included a first heating step from 0 to $200^{\circ} \mathrm{C}$ at $10^{\circ} \mathrm{C} / \mathrm{min}$, a cooling step from 200 to $0^{\circ} \mathrm{C}$ at $10^{\circ} \mathrm{C} / \mathrm{min}$ and a second heating step from 0 to $200^{\circ} \mathrm{C}$ at $10^{\circ} \mathrm{C} / \mathrm{min}$. Glass transition temperatures $\left(\mathrm{T}_{\mathrm{g}}\right)$ of the (co)polymers were measured during the second heating step. (Co)polymers were dried under vacuum for $24 \mathrm{~h}$ prior analysis.

Turbidimetry analysis. Turbidimetry measurements of the (co)polymers solutions ( $0.3 \mathrm{wt} \%$ in water) were performed with a Shimadzu UV-2450PC spectrophotometer, from $13{ }^{\circ} \mathrm{C}$ to $33^{\circ} \mathrm{C}$ (heating/cooling rate: $0.5{ }^{\circ} \mathrm{C} \cdot \mathrm{min}^{-1}$ ). Transmittance at $500 \mathrm{~nm}$ was plotted versus the temperature. The minimum of the first-order derivative fit of transmittance versus temperature was considered as the temperature of cloud point $\left(\mathrm{T}_{\mathrm{cp}}\right)$ (see Figure 9).

\section{RESULTS AND DISCUSSION}

\section{RAFT/MADIX copolymerization of VAc/VCL: evaluation of control}

First, the level of control of RAFT/MADIX (co)polymerization of vinyl acetate and $\mathrm{N}$ vinylcaprolactam mediated by the $O$-ethyl-S-(1-ethoxycarbonyl)ethyldithiocarbonate transfer agent (Scheme 1) was investigated. The polymerizations were carried out in bulk at $65^{\circ} \mathrm{C}$ with varying initial monomer feed ratios $\left(f_{\mathrm{VAc}, 0}\right)$ as reported in Table S.1 (Supporting Information). Both VAc and VCL monomers being liquid at $65^{\circ} \mathrm{C}$, the polymerization was performed in bulk in order to limit the use of toxic and/or flammable polar solvents such as 1,4-dioxane, chloroform, N,N-dimethylformamide or anisole, which were previously used as solvents for RAFT (co)polymerization of VCL with other less activated monomers. ${ }^{7,9,}$ 10, 12, 30

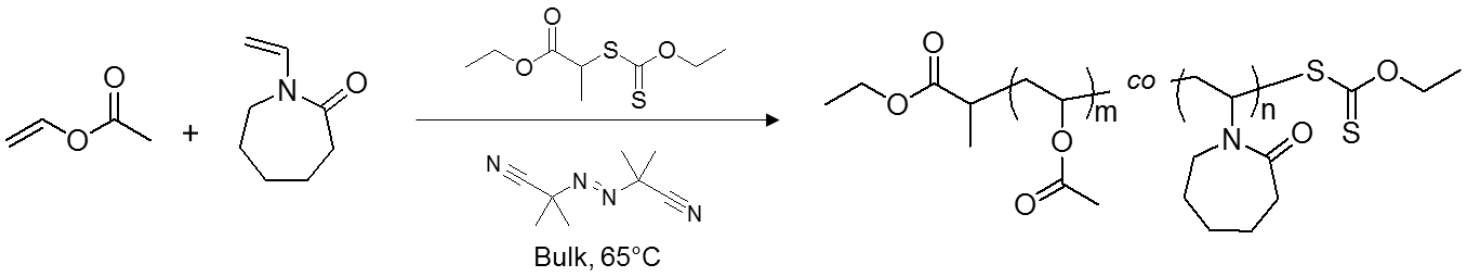

Scheme 1. Synthesis of P(VAc-co-VCL) copolymers by RAFT/MADIX polymerization mediated by $O$-ethyl-S-(1-ethoxycarbonyl)ethyldithiocarbonate (= xanthate chain transfer agent, CTA) in bulk. 
The semilogarithmic kinetic plots of the overall molar monomer conversion versus time are linear in the initial range of conversions but some plots curve upwards for higher conversions indicating a steady increase in propagating radical concentration (Figure 1). Such an inhibition period of 60 to 180 minutes was observed in the kinetic plots. Such inhibition period was previously observed in xanthate-mediated vinyl acetate polymerization and was ascribed to the vulnerability of the reactive vinyl acetate propagating radical towards oxygen and by-products generated during the CTA synthesis. ${ }^{28,} 29$ The induction period may also be due to initial selective formation of monoadduct but the length of the inhibition period did not show a specific trend with the initial VAc molar feed ratio. A similar range of molar conversion in monomers $(40-60 \%)$ was reached within 6 hours of RAFT polymerization carried out at $65^{\circ} \mathrm{C}$ for the entire range of the initial VAc feed composition $\left(0<f_{\mathrm{VAc}}<1\right.$, Table 1). Note that a significant increase in the time required to reach $30 \%$ monomer conversion for Co-MRP copolymerization of VAc and VCL was previously reported for $f_{\mathrm{VAc}, 0}>0.4$ (48 to $\left.115 \mathrm{~h}\right) .^{13}$

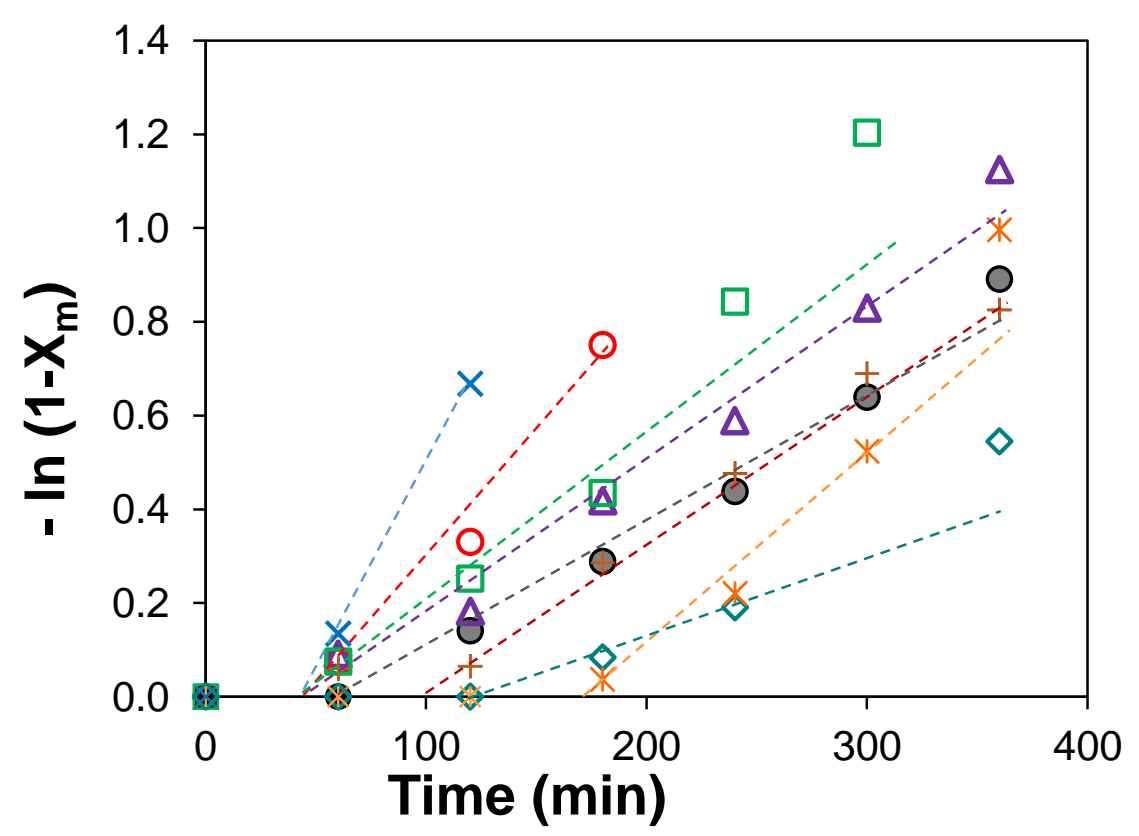

Figure 1. Semilogarythmic plots of overall molar monomer conversion $\left(X_{\mathrm{m}}\right)$ versus time : $\times$ $f_{\mathrm{VAc}, 0}=0, \diamond f_{\mathrm{VAc}, 0}=0.15, \bigcirc f_{\mathrm{VAc}, 0}=0.30,+f_{\mathrm{VAc}, 0}=0.52, \square f_{\mathrm{VAc}, 0}=0.62, \Delta f_{\mathrm{VAc}, 0}=0.71$, $f_{\mathrm{VAc}, 0}=0.87$ and $* f_{\mathrm{VAc}, 0}=1($ expt 1-8 in Table 1).

The experimental molar masses of the series of P(VAc-co-VCL) copolymers increase linearly with the overall monomer weight conversion (Figure 2) in accordance with equation 11. The low dispersity $(\bigoplus)$ values of the final (co)polymers which range between 1.25 and 1.04 are consistent with a controlled character of the RAFT/MADIX (co)polymerization mediated by $O$-ethyl-S-(1-ethoxycarbonyl)ethyldithiocarbonate chain transfer agent (Table 1). Moreover, 
the decrease of dispersity (Figure 2) and the shift of SEC chromatograms toward low elution volumes throughout the copolymerization reactions (Figure 3) both support the controlled character of the RAFT copolymerizations at each monomer feed ratio.

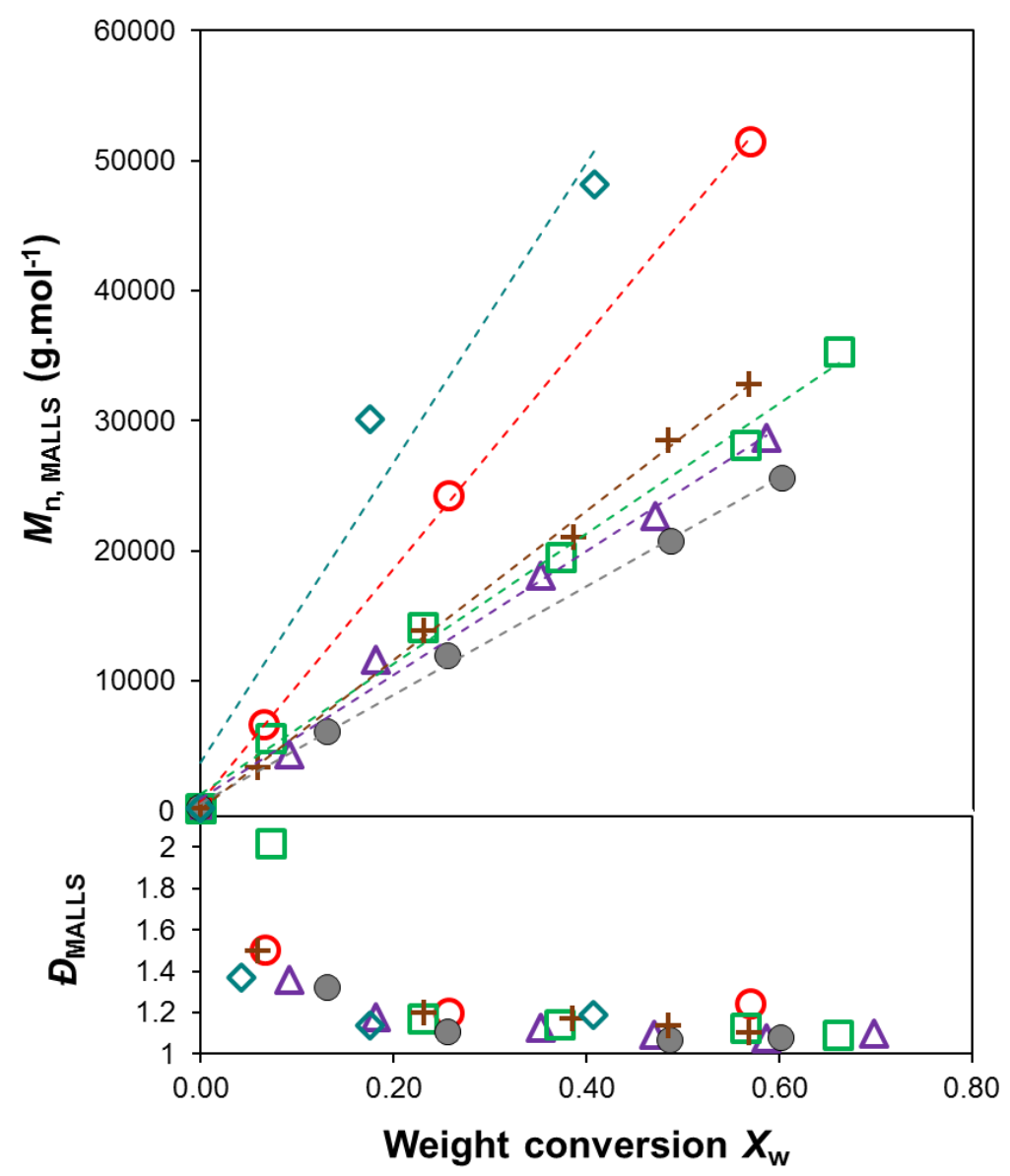

Figure 2. Evolution of $M_{\mathrm{n}, \mathrm{MALLS}}$ and dispersity versus the overall weight conversion $\left(X_{\mathrm{w}}\right)$ for: $\diamond f_{\mathrm{VAc}, 0}=0.15, \bigcirc f_{\mathrm{VAc}, 0}=0.30,+f_{\mathrm{VAc}, 0}=0.52, \square f_{\mathrm{VAc}, 0}=0.62, \Delta f_{\mathrm{VAc}, 0}=0.71, \bigcirc f_{\mathrm{VAc}, 0}=0.87$ (expt 2-7 in Table 1). 


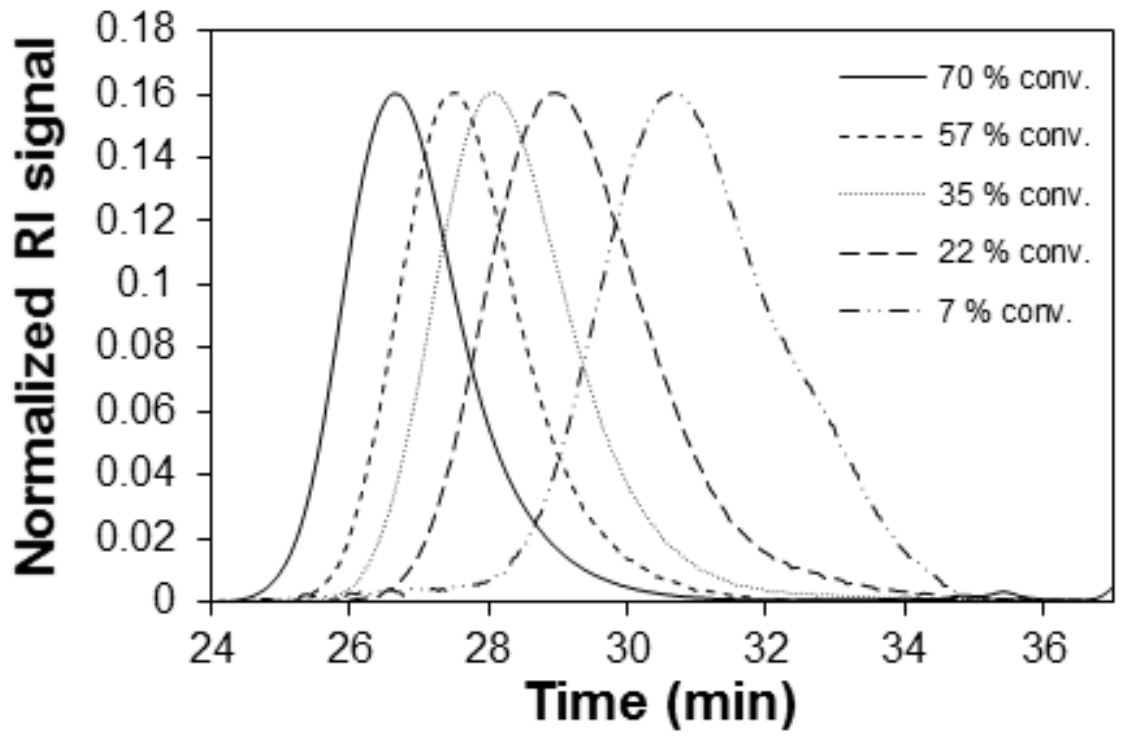

Figure 3. Evolution of the size exclusion chromatograms with monomer conversion for xanthate mediated VAc/VCL copolymerization with $f_{\mathrm{VAc}, 0}=0.62$ (expt 5 in Table 1).

The experimental $M_{\mathrm{n}}$ are greater than the theoretical ones, which implies that the RAFT agent is not fully consumed during the course of the polymerization. The xanthate CTA exhibits the characteristic absorption band of a dithiocarbonate group at $\lambda=355 \mathrm{~nm}$ (see Figure S.5a in Supporting Information). Thus, the presence of an additional peak at low elution volume (35.5 $\mathrm{mL}$ ) observed in the UV-visible SEC traces of the final copolymers (recorded at $\lambda=355 \mathrm{~nm}$ ) confirms the incomplete consumption of the xanthate chain transfer agent (CTA) (see Figure S.5b, Supporting Information). The efficiency of the xanthate CTA, calculated on the basis of the ratio between theoretical and experimental $M_{\mathrm{n}}$ rises with the increase of the initial VAc molar fraction (Table 1). Such enhancement of CTA efficiency is supported by the analysis of the UV-visible traces of the SEC chromatograms of the final copolymers which depict a decrease in the relative height of the residual CTA peak for higher initial VAc molar fractions (see Figure S.5b in Supporting Information). In summary, both the increase of xanthate efficiency and the decrease of dispersity values (Table 1) by increasing $f_{\mathrm{VAc}, 0}$ from 0 to 1 converge to show that the chain transfer constant to xanthate agent $\left(C_{\mathrm{tr}}=k_{\mathrm{tr}} / k_{\mathrm{p}}\right)$ is higher for RAFT polymerization of VAc than of VCL. A value of $C_{\text {tr }}$ of 25 was reported for $O$-ethyl- $S$ (1-ethoxycarbonyl)ethyldithiocarbonate mediated VAc polymerization, ${ }^{56}$ but no value of $C_{\text {tr }}$ has been reported for the RAFT polymerization of VCL mediated by this xanthate agent. While an increase of dispersity values for higher levels of VAc was reported for the synthesis of P(VAc- 
co-VCL) copolymers by Co-MRP, ${ }^{13}$ the present work shows a better control of RAFT VCL/VAc copolymerization by increasing the initial VAc feed ratio.

Table 1. Final compositions and macromolecular features of the P(VAc-co-VCL) copolymers synthesized by RAFT/MADIX copolymerization in bulk at $65^{\circ} \mathrm{C}$.

\begin{tabular}{|c|c|c|c|c|c|c|c|c|c|}
\hline Expt & $f_{\mathrm{VAc}, 0^{\mathrm{a}}}$ & $\begin{array}{l}X_{\mathbf{m}} \mathbf{b} \\
\%\end{array}$ & $\begin{array}{l}X_{\mathbf{w}^{\mathrm{c}}} \\
\%\end{array}$ & $F_{\mathrm{VAc}}{ }^{\mathrm{d}}$ & $\begin{array}{l}\boldsymbol{d n}_{\boldsymbol{n}} / \boldsymbol{d} \boldsymbol{c}_{\text {polymer }}{ }^{\mathrm{e}} \\
m L \cdot g^{-1}\end{array}$ & $\begin{array}{l}M_{\mathbf{n}, \text { theo }} \mathbf{f} \\
\text { g. } \mathrm{mol}^{-1}\end{array}$ & $\begin{array}{l}\text { Mn,MALLS }^{\mathbf{g}} \\
\text { g. } \text { ol }^{-1}\end{array}$ & Ð MALLS $^{\mathrm{g}}$ & $M_{\mathrm{n}, \text { theo }} / M_{\mathrm{n}, \mathrm{MALLS}}$ \\
\hline $\mathbf{1}$ & 0 & 56 & 56 & 0 & 0.109 & 30519 & 45330 & 1.12 & 0.67 \\
\hline 2 & 0.15 & 41 & 41 & 0.19 & 0.103 & 20510 & 48190 & 1.19 & 0.43 \\
\hline 3 & 0.30 & 51 & 52 & 0.28 & 0.099 & 25237 & 51530 & 1.25 & 0.49 \\
\hline 4 & 0.52 & 56 & 57 & 0.49 & 0.090 & 23669 & 32840 & 1.11 & 0.72 \\
\hline 5 & 0.62 & 63 & 66 & 0.53 & 0.088 & 25504 & 35370 & 1.10 & 0.72 \\
\hline 6 & 0.71 & 56 & 59 & 0.63 & 0.083 & 23029 & 28650 & 1.08 & 0.80 \\
\hline 7 & 0.87 & 59 & 60 & 0.83 & 0.071 & 21695 & 25660 & 1.08 & 0.85 \\
\hline 8 & 1 & 63 & 63 & 1 & 0.058 & 21085 & 23380 & 1.04 & 0.90 \\
\hline
\end{tabular}

${ }^{\mathrm{a}} f_{\mathrm{VAc}, 0}$ is the VAc molar fraction in the initial mixture; ${ }^{\mathrm{b}} X_{\mathrm{m}}$ is the overall monomer molar conversion at $6 \mathrm{~h}$, equation $2 ;{ }^{\mathrm{c}} X_{\mathrm{w}}$ is the overall monomer weight conversion at $6 \mathrm{~h}$, equation 3 ; ${ }^{\mathrm{d}} F_{\mathrm{VAc}}$ is the molar fraction of the monomer into the copolymer, equation 4 ; ${ }^{\mathrm{e}}$ Refractive index increment of the copolymer in THF determined from equation $12 ;^{\mathrm{f}}$ Theoretical number-average molar mass from equation $11 ;^{\mathrm{g}}$ Values obtained from the SEC analysis with a MALLS detector.

The perfect overlay of the UV-visible $(\lambda=355 \mathrm{~nm})$ and RI traces of the SEC chromatograms observed for the series of $\mathrm{P}(\mathrm{VAc}-\mathrm{co}-\mathrm{VCL})$ copolymers depicts the presence of the dithiocarbonate chain-end and so the living character on the entire molar mass distribution (see

Figure S.6, Supporting Information).

\section{Determination of reactivity ratios and $\mathrm{P}(\mathrm{VAc}-\mathrm{co}-\mathrm{VCL})$ microstructure.}

Reactivity ratios are most often calculated using a linearization of the Mayo-Lewis equation ${ }^{57}$ (either the differential or integrated form). The Kelen-Tüdos (KT) method is one of the most common methods (see details in Supporting Information). ${ }^{58}$ The authors later modified the method in order to limit large systemic error in calculation due to the low conversion assumption. The extended Kelen-Tüdos method takes into account the individual monomer conversions. ${ }^{59}$ As reported in Table 2, similar values of reactivity ratios were calculated from either the Kelen-Tüdos method or the extended Kelen-Tüdos method for RAFT copolymerization of VAc and VCL performed in bulk at $65^{\circ} \mathrm{C}$ (Table 1) ( $r_{\mathrm{VAc}}=0.43$ and $r_{\mathrm{VCL}}$ $=0.20$ Table 2). Nonlinear least square (NLLS) methods can also be used to determine the reactivity ratios (see details in Supporting Information). ${ }^{60-63}$ The sum of the squares of the residuals was minimized to set the values of reactivity ratios fitting the experimental copolymer composition, $F_{\mathrm{VAc}}$ calculated from the individual monomer conversion (equation 4 ) with the 
theoretical copolymer composition calculated from the Mayo-Lewis equation ${ }^{57}\left(F_{\mathrm{VAc}}\right.$, theo, equation 13).

$F_{\mathrm{A}, \text { theo. }}=\frac{r_{\mathrm{A}} \times f_{\mathrm{A}}^{2}+f_{\mathrm{A}} \times f_{\mathrm{B}}}{r_{\mathrm{A}} \times f_{\mathrm{A}}^{2}+2 \times f_{\mathrm{A}} \times f_{\mathrm{B}}+r_{\mathrm{B}} \times f_{\mathrm{B}}^{2}} \quad$ Equation 13

The theoretical data of the $F_{\mathrm{VAc}}=f\left(f_{\mathrm{VAc}, 0}\right)$ plots fit the experimental data for values of reactivity ratios of $r_{\mathrm{VAc}}=0.37$ and $r_{\mathrm{VCL}}=0.16$ (Figure 4). This $S$ profile is in good agreement with the evolution of the individual monomer conversion versus time displayed in Figure 4. Indeed, for initial VAc fraction below the azeotropic composition $\left(f_{\mathrm{VAc}, 0, \text { azeotropic }}=\frac{\left(1-r_{\mathrm{VCL}}\right)}{\left(2-r_{\mathrm{VCL}}-r_{\mathrm{VAc}}\right)}=\right.$ 0.57), VAc is more rapidly consumed than VCL while the opposite trend is observed for $f_{\mathrm{VAc}, 0}$

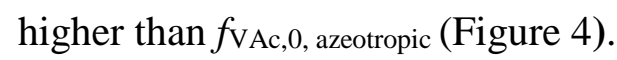

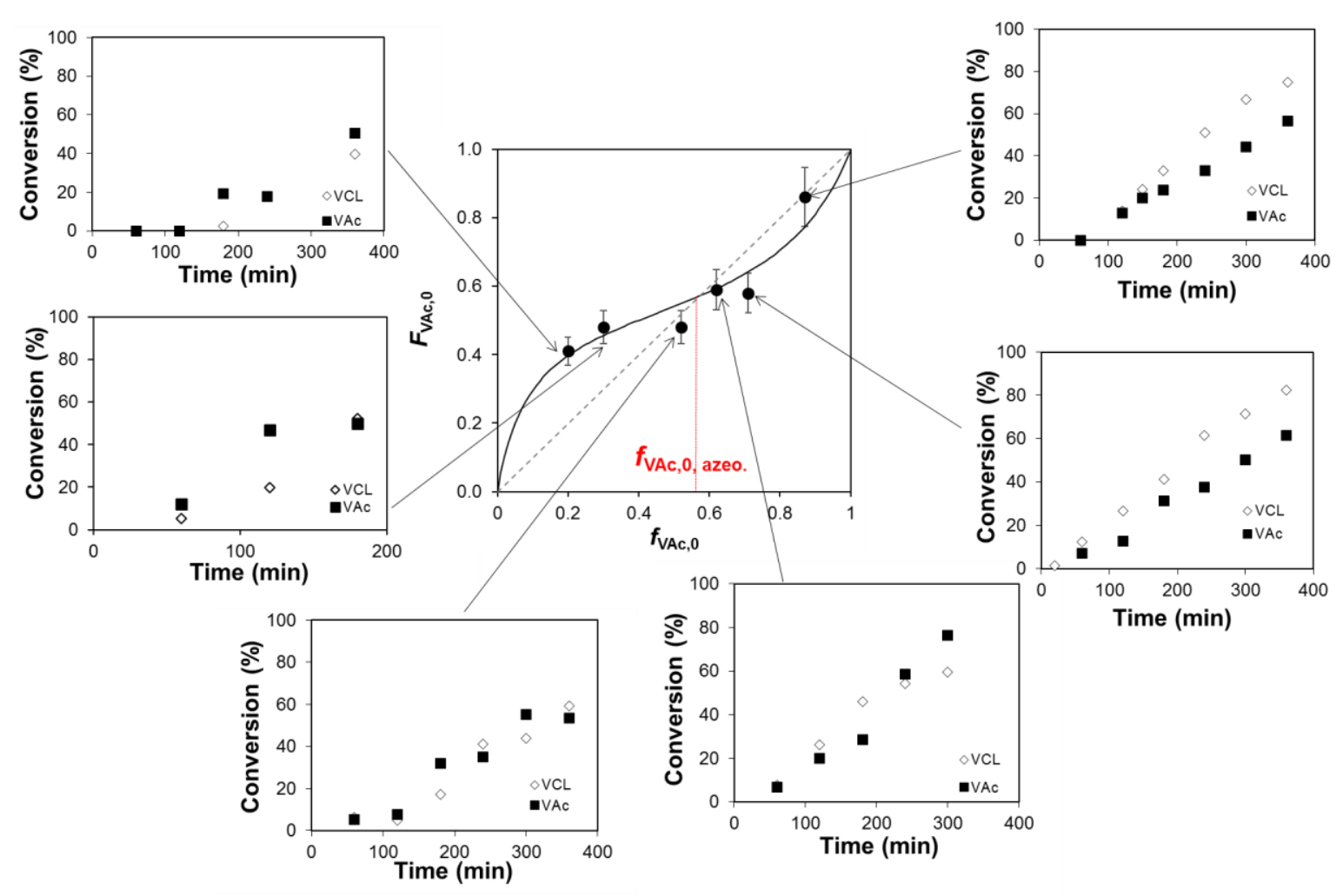

Figure 4. Experimental values of $F_{\mathrm{VAc}, 0}(\mathbf{)})$ versus $f_{\mathrm{VAc}, 0}$ and evolution of monomer individual conversions with time for different monomer initial molar feed ratios. The black curve corresponds to the non-linear fit of Lewis-Mayo equation with $r_{\mathrm{VAc}}=0.37$ and $r_{\mathrm{VCL}}=0.16$. The dotted line is the azeotropic curve. The error bar was set on the basis of the error bar from NMR technique used to determine $F_{\mathrm{VAc}, 0 \text {. }}$

The second nonlinear least squares method is based on the integrated form of the copolymerization equation. ${ }^{64,65}$ Equation 14 accurately describes the drift of the monomer feed ratio $\left(f_{\mathrm{VAc}}\right)$ over the course of copolymerization in relationship with the values of reactivity 
ratios. This composition drift model provides an enhanced number of analyzed experimental data and therefore the curve fitting method decreases the uncertainty of reactivity ratio measurements.

$X_{m}=1-\left(\frac{f_{\mathrm{A}}}{f_{\mathrm{A}, 0}}\right)^{\alpha} \times\left(\frac{f_{\mathrm{B}}}{f_{\mathrm{B}, 0}}\right)^{\beta} \times\left(\frac{f_{\mathrm{A}, 0}-\delta}{f_{\mathrm{A}}-\delta}\right)^{\gamma} \quad$ Equation 14

Where $X_{\mathrm{m}}$ is the overall molar monomer conversion, $=\frac{r_{\mathrm{B}}}{1-r_{\mathrm{B}}}, \beta=\frac{r_{\mathrm{A}}}{1-r_{\mathrm{A}}}, \gamma=\frac{1-r_{\mathrm{A}} \times r_{\mathrm{B}}}{\left(1-r_{\mathrm{A}}\right) \times\left(1-r_{\mathrm{B}}\right)}$ and $\delta=\frac{1-r_{\mathrm{B}}}{2-r_{\mathrm{A}}-r_{\mathrm{B}}}$. The composition of the monomer feed was calculated from equation 15 .

$f_{\mathrm{A}}=\frac{f_{\mathrm{A}, 0} \times\left(1-x_{\mathrm{A}}\right)}{f_{\mathrm{A}, 0} \times\left(1-x_{\mathrm{A}}\right)+\left(1-f_{\mathrm{A}, 0}\right) \times\left(1-x_{\mathrm{B}}\right)} \quad$ Equation 15

The experimental values of $f_{\mathrm{VAc}}$ and $X_{\mathrm{m}}$ were fitted to the integrated form of the copolymer composition equation (equation 14) using the visualization of the sum of squares space method. ${ }^{61,66} \mathrm{We}$ calculated the reactivity ratios as $r_{\mathrm{VAc}}=0.33$ and $r_{\mathrm{VCL}}=0.29$. The point estimates and $95 \%$ joint confidence interval are displayed in Figure 5. The interval for $r_{\mathrm{VAc}}$ (0.24-0.45) is slightly narrower than for $r_{\mathrm{VCL}}(0.15-0.49)$.

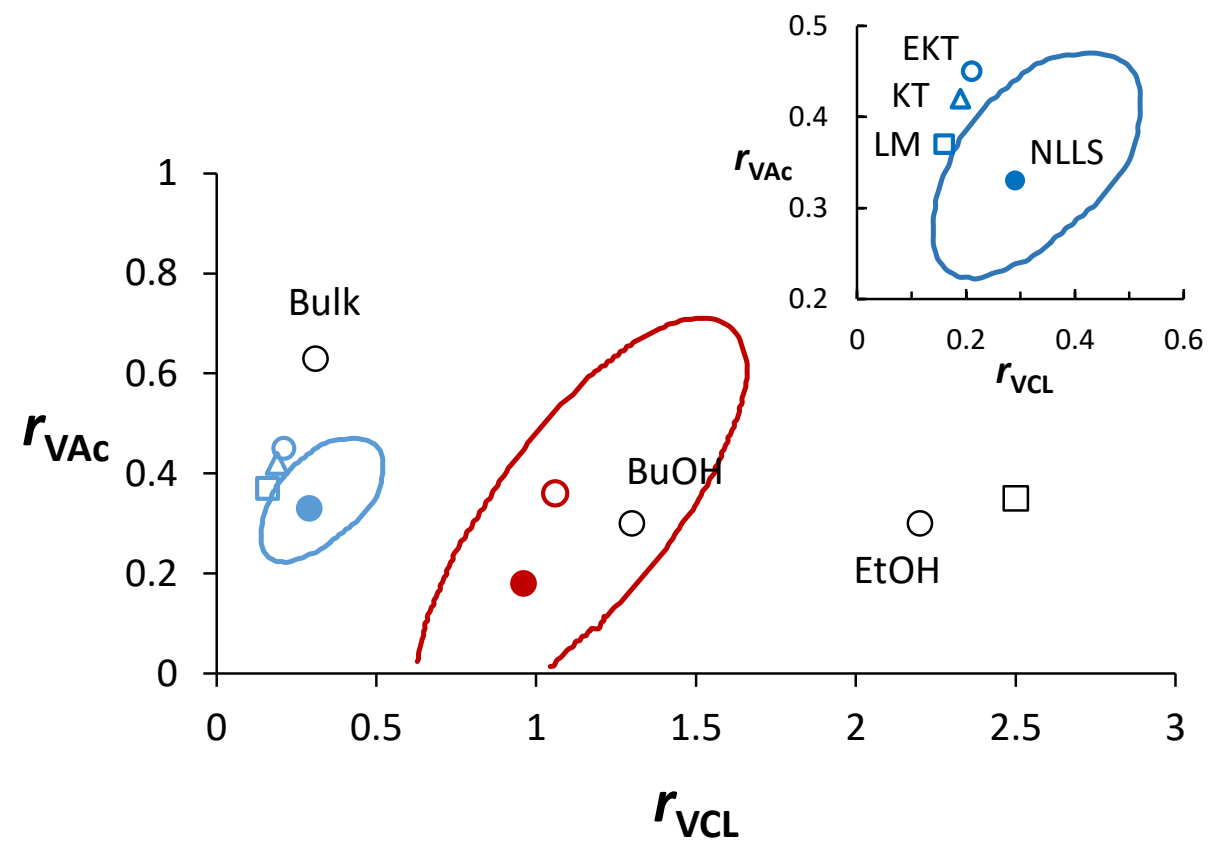

Figure 5. Reactivity ratios (points) and $95 \%$ joint confidence regions (lines) for copolymerizations of VAc and VCL. Blue: data of the present work. Red: data from reference ${ }^{13}$ (open circle: reported reactivity ratios; closed circle and line: best estimate and 95\% joint confidence region from NLLS fitting of Skeist equation of their experimental data). Black: circles data from reference ${ }^{49}$ in various solvents and square from references ${ }^{51}$ (solvent not 
specified). Inset: reactivity ratios calculated from this work using various methods: KT: KelenTudős at low conversion; EKT: Extended Kelen-Tudös; LM: fitting Lewis-Mayo at low conversion; NLLS: NLLS fitting to Skeist equation (with 95\% joint confidence region).

The theoretical plots of $f_{\mathrm{VAc}}$ versus $X_{\mathrm{m}}$ perfectly fit the experimental data during the course of polymerization for the whole series of VAc/VCL copolymerizations (Figure 6). The composition drift is rather limited for initial VAc molar fraction above 0.5 , but it is slightly more pronounced for lower initial fractions of VAc $\left(f_{\mathrm{VAc}, 0}<0.4\right)$. Regarding plots of Figure 6, the formation of statistical copolymers with homogeneously distributed VAc and VCL units is expected as the overall monomer conversion was limited to $70 \%$ for the series of copolymers (Table 1).

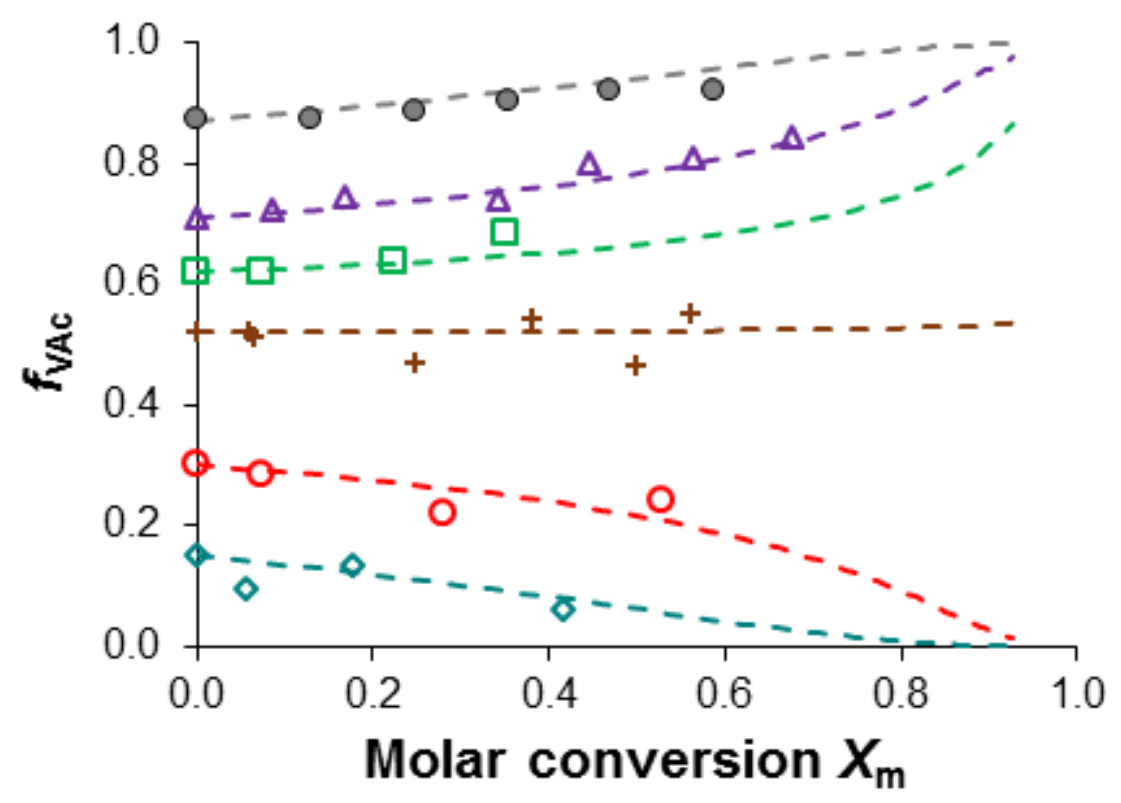

Figure 6. Variation of the VAc composition in the monomer feed $\left(f_{\mathrm{VAc}}\right)$ versus the molar conversion. Symbols: plots of experimental data of $f_{\mathrm{VAc}}$ (equation 15) versus $X_{\mathrm{m}}, \diamond f_{\mathrm{VAc}, 0}=$ $0.15, \bigcirc f_{\mathrm{VAc}, 0}=0.30,+f_{\mathrm{VAc}, 0}=0.52, \square f_{\mathrm{VAc}, 0}=0.62, \Delta f_{\mathrm{VAc}, 0}=0.71, \bigcirc f_{\mathrm{VAc}, 0}=0.87$; The dotted lines correspond to the calculated values of $X_{\mathrm{m}}$ (equation 14) for given theoretical values of $f_{\mathrm{VAc}}$.

Table 2 summarizes the values of reactivity ratio of VAc and VCL calculated in the present work with linearization techniques or nonlinear least squares methods. As depicted in Figure $\mathbf{5}$, the three sets of reactivity ratios calculated from KT, extended KT and Lewis Mayo NLLS method (equation 13) were at the close outer limit of the $95 \%$ joint confidence interval (Figure 5). The two first methods take into account the copolymer composition at low conversion. As previously reported by Klumpermann et al., ${ }^{67}$ the RAFT agent can influence the monomer 
selectivity at the early stages of polymerization. Also, previous studies revealed an impact of the RDRP equilibrium implemented by reversible termination on the copolymer composition for very low monomer conversion. ${ }^{68}$ Not only did the reactivity ratios reported in the literature exhibit discrepancy between their values, their values were out of the range of the present $95 \%$ joint confidence interval. One reason for very different reactivity ratios between this work and the study of Kermagoret et al. ${ }^{13}$ might be accounted to the difference between RAFT polymerization and Co-MRP.

Table 2. VAc and VCL reactivity ratio values calculated from the different methods.

\begin{tabular}{lcc}
\hline Method & $\boldsymbol{r V A c}$ & $\boldsymbol{r V C L}$ \\
\hline Kelen-Tüdos (KT) & 0.42 & 0.19 \\
Extended Kelen-Tüdos (e-KT) & 0.45 & 0.21 \\
NLLS method based on Lewis-Mayo equation (equation 13) & 0.37 & 0.16 \\
NLLS method based on the integrated form of the & \\
copolymerization equation (equation 14) & & 0.33 \\
\hline
\end{tabular}

$\mathrm{P}(\mathrm{VAc}-\mathrm{co}-\mathrm{VCL})$ copolymers with different monomer compositions (expt 5 and 7 in Table 1) were analyzed by ${ }^{13} \mathrm{C}$ NMR and the spectra were compared to PVCL and PVAc spectra. The integrality of the spectra is shown in Figure S.7 (Supporting Information) and two zones of interest are displayed in Figure 7. It can be noticed that the characteristic signal of each polymeric unit is influenced by the presence of the neighbor comonomer distributed homogeneously along the chain. For instance, the methine signal $\left(\mathrm{CH}_{\text {II }}, 65-70 \mathrm{ppm}\right.$, Figure 7.b) of PVAc broadens by increasing the fraction of VCL. 
(a)

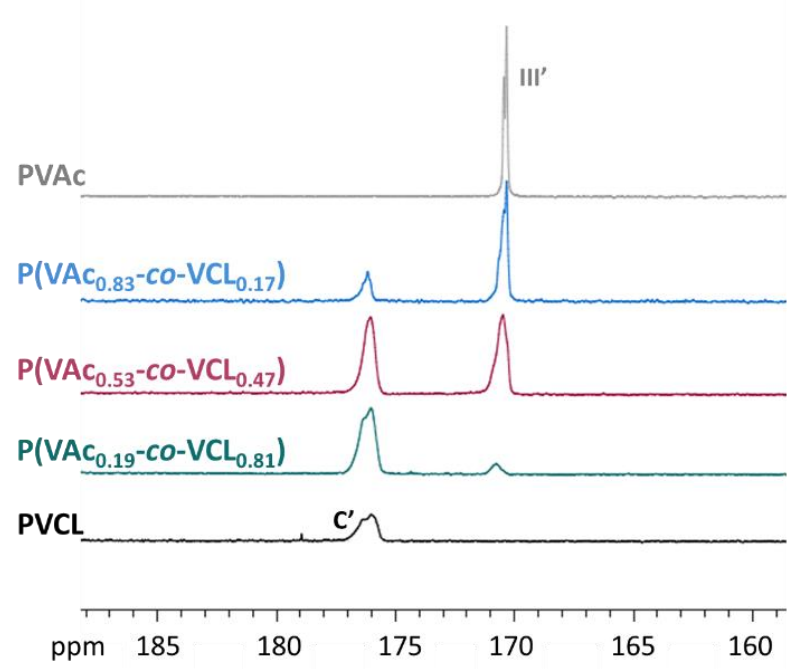

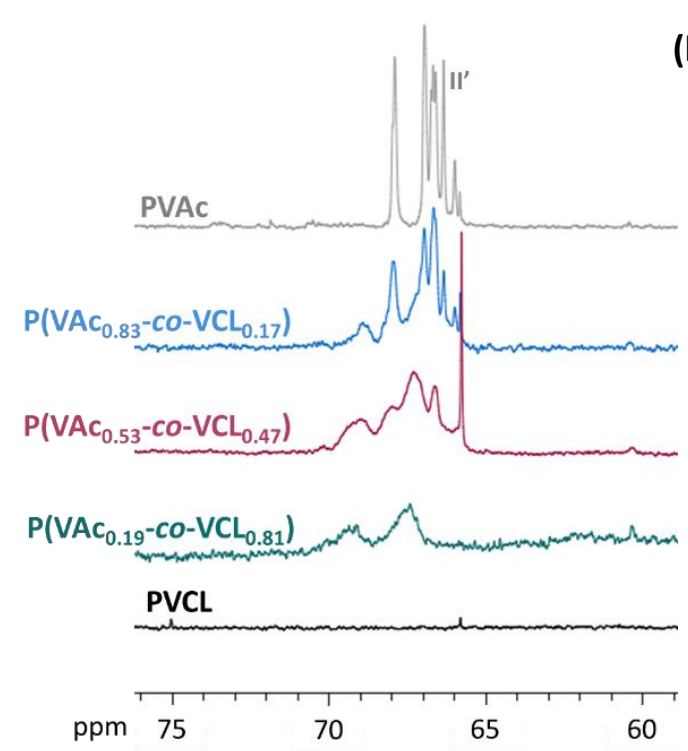

(b)

Figure 7. ${ }^{13} \mathrm{C}$ NMR spectra of PVAc, PVCL, P(VAc $\left.0.19-c o-\mathrm{VCL}_{0.81}\right)$ (expt 2 in Table 1), $\mathrm{P}\left(\mathrm{VAc}_{0.53}-\mathrm{co}-\mathrm{VCL}_{0.47}\right)$ (expt 5 in Table 1$)$ and $\mathrm{P}\left(\mathrm{VAc}_{0.83}-\mathrm{co}-\mathrm{VCL}_{0.17}\right)$ (expt 7 in Table 1) (co)polymers in $\mathrm{CDCl}_{3}$ : (a) zoom on the PVAc and PVCL carbonyl signal range; (b) zoom on the PVAc methine signal range.

The copolymer compositions can be calculated on the basis of the integrals of the well-resolved carbonyl signals at $170-180 \mathrm{ppm}$ of each polymer unit of the P(VAc-co-VCL) copolymer (Table S.2, Supporting Information). Such ${ }^{13} \mathrm{C}$ NMR compositions match the compositions calculated either from the individual monomer conversions (Equation 4) or from the integrals of the proton NMR spectra of the copolymers (Table S.2 and Figure S.8 in Supporting Information). The $\mathrm{P}(\mathrm{VAc}-\mathrm{co}-\mathrm{VCL})$ final (co)polymers exhibit a unique glass transition temperature $\left(T_{\mathrm{g}}\right)$ characterized by differential scanning calorimetry (Table S.3, Supporting Information). The good agreement between the experimental $\mathrm{T}_{\mathrm{gS}}$ of copolymers and the theoretical ones calculated from Fox-Flory equation (equation 16) (see Figure 8 and Table S.3, Supporting Information) confirms the homogeneous distribution of VAc and VCL monomer in the P(VAc-co-VCL) chain.

$\frac{1}{T_{\mathrm{g}, \text { theo } \mathrm{P}(\mathrm{VAc}-\mathrm{co}-\mathrm{VCL})}}=\frac{w_{\mathrm{VAc}}}{T_{\mathrm{g}, \mathrm{PVAc}}}+\frac{w_{\mathrm{VCL}}}{T_{\mathrm{g}, \mathrm{PVCL}}} \quad$ Equation 16 


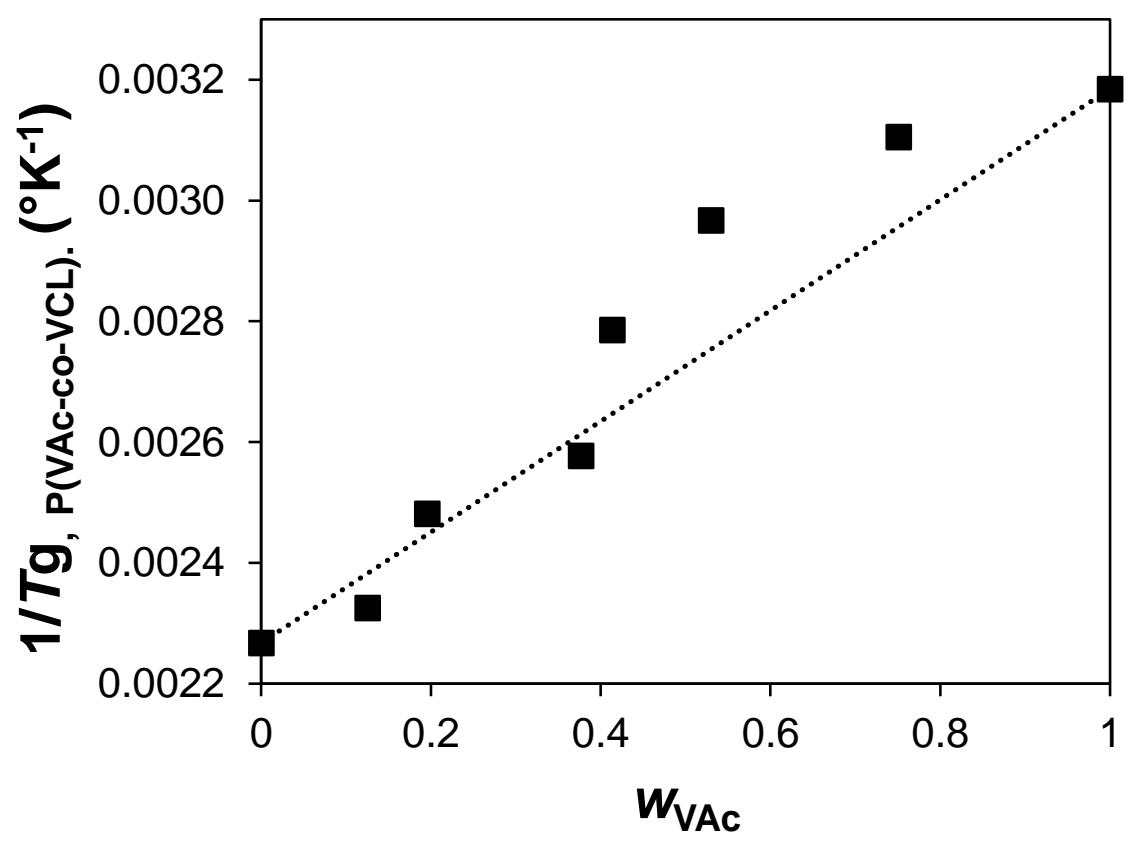

Figure 8. Experimental glass transition temperature of the P(VAc-co-VCL) copolymers as a function of the weight fraction of VAc in the copolymer (equation 5); Dotted line: theoretical glass transition temperature of the copolymers calculated from equation 16.

\section{Thermoresponsive self-assembly of $\mathrm{P}(\mathrm{VAc}-\mathrm{co}-\mathrm{VCL})$ copolymers in water.}

Thermoresponsive polymers change their hydration state in water in response to a change of temperature. Above the lower critical solution temperature (LCST), poly( $N$-vinylcaprolactam) (PVCL) undergo a conformation phase transition in water between a soluble and insoluble state. The polar amide group of PVCL creates favorable association with surrounding water molecules by hydrogen bonding below the LCST and hydrophobic interactions (sevenmembered ring) predominates above the LCST. ${ }^{8,69}$ The phase transition temperature of PVCL is in the physiological range $\left(30-40{ }^{\circ} \mathrm{C}\right)^{3-5}$ and can be tuned by the polymer concentration ${ }^{40}$ and its molar mass. ${ }^{9}$ The incorporation of a co-monomer unit is an additional parameter to modify the temperature of cloud point $\left(\mathrm{T}_{\mathrm{cp}}\right)$. As depicted in Figure 9, a dependence of the phase transition temperature with the copolymer composition is observed by turbidimetry analysis. For low VAc content $\left(F_{\mathrm{VAc}}=0-0.28\right)$, the polymers in water exhibit a sharp and reversible thermal transition between a clear solution and a cloudy solution above a certain temperature ( $\left.\mathrm{T}_{\text {cloud point }}\right)$. This transition is broadened for a higher content of hydrophobic $\mathrm{VAc}\left(F_{\mathrm{VAc}}=0.53\right)$ but reversibility is still observed. The hysteresis never exceeds 2 degrees (Figure 9). 


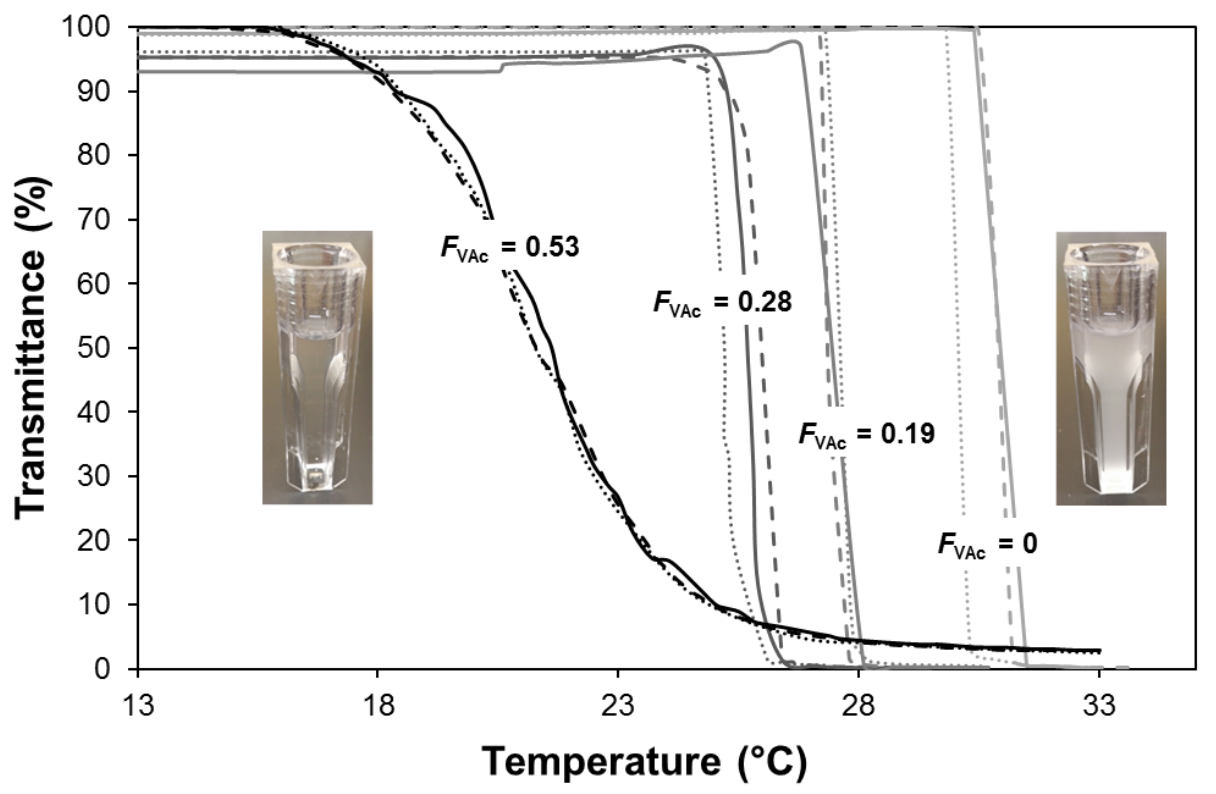

Figure 9. Transmittance at $\lambda=500 \mathrm{~nm}$ versus temperature for aqueous solution $\left(3 \mathrm{~g} . \mathrm{L}^{-1}\right)$ of: $\mathrm{P}\left(\mathrm{VAc}_{0.53-c o}-\mathrm{VCL}_{0.47}\right)$ copolymer (expt 5 in Table 1), $\mathrm{P}\left(\mathrm{VAc}_{0.28-}-\mathrm{co}^{-\mathrm{VCL}_{0.72}}\right.$ ) copolymer (expt 3 in Table 1), $\mathrm{P}\left(\mathrm{VAc}_{0.19}-\mathrm{co}_{-} \mathrm{VCL}_{0.81}\right)$ copolymer (expt 2 Table 1) and $\mathrm{P}(\mathrm{VCL})$ homopolymer (expt 1 in Table 1); Full line (-): First heating, Dashed line (- - -): Cooling, Dotted line ( $\cdots)$ : Second heating; Photos of the solutions below (left) and above (right) the cloud point.

The phase transition temperatures were also measured by means of dynamic light scattering (DLS). Figure S.9 in Supporting Information shows the evolution of the hydrodynamic diameter $\left(D_{\mathrm{h}}\right)$ as a function of temperature. The increase of $D_{\mathrm{h}}$ from $7 \mathrm{~nm}$ to $1.2 \mu \mathrm{m}$ for $\mathrm{P}\left(\mathrm{VAc}_{0.19}-\mathrm{co}-\mathrm{VCL}_{0.81}\right)$ reveals the formation of very large aggregates above the transition temperature. The cloud point temperatures obtained by DLS were consistent with the ones measured by UV-visible spectroscopy (Table 3). The increasing incorporation of hydrophobic VAc units into PVCL thermoresponsive chains leads to a decrease of the copolymer cloud point temperature (Figure S.10). As the hydrophobic composition of the copolymers is increased, the hydrogen bonding effect between the copolymer chains and water is lowered while hydrophobic interactions are enhanced, thus lowering the required energy to collapse (i.e., lower $\left.T_{\mathrm{cp}}\right){ }^{10,11}$ The characteristics of the P(VAc-co-VCL) copolymers dispersed in water were studied by means of dynamic and static light scattering at a temperature below the cloud point temperature (see Table 3).

Table 3. Characteristics of P(VAc-co-VCL) copolymers dispersed in water.

\begin{tabular}{|c|c|c|c|c|c|c|c|}
\hline Expt & $F_{\text {VAc }}$ & $\begin{array}{l}T_{\text {cp }, \mathrm{UV} \text {-vis }}{ }^{a} \\
{ }^{\circ} \mathrm{C}\end{array}$ & $\begin{array}{l}T_{\text {cp, DLS }}{ }^{b} \\
{ }^{\circ} \mathrm{C}\end{array}$ & $\begin{array}{l}T^{c} \\
{ }^{\circ} C\end{array}$ & $\begin{array}{l}M_{\mathbf{w}, \mathbf{S L S}^{d}} \\
{\text { g. } \mathrm{mol}^{-1}}\end{array}$ & $N_{\text {agg. }}{ }^{d}$ & $\begin{array}{l}\boldsymbol{D}_{\mathbf{h}, \mathbf{D L S}} \\
n m\end{array}$ \\
\hline 2 & 0.19 & $27.4 \pm 0.4$ & 32.7 & 25 & 52100 & 1 & 6.9 \\
\hline
\end{tabular}




$\begin{array}{llllllll}\mathbf{3} & 0.28 & 25.5 \pm 0.5 & 29.1 & 25 & 42200 & 1 & 5.6 \\ \mathbf{5} & 0.53 & 21.4 \pm 0.1 & - & 10 & 97600 & 3 & 22.5\end{array}$

${ }^{a}$ Cloud point temperature measured by UV-visible spectroscopy of solution of copolymers at 3 g. $\mathrm{L}^{-1}$ in water, the given value is the average of the cloud point temperature values obtained for the first heating, cooling, and second heating; ${ }^{b}$ Cloud point temperature measured by dynamic light scattering of solution of copolymers at 5 g.L. ${ }^{-1}$ in water; ${ }^{c}$ Temperature of the static light scattering measurements; ${ }^{d}$ Data measured on ALV setup (see experimental part, SLS and DLS) at the temperature of measurement reported in this Table 3, which corresponds to a temperature below the cloud point.

At all concentrations the DLS analyses of P(VAc-co-VCL) copolymers dispersed in water revealed a main population of small aggregates (fast mode of relaxation) with hydrodynamic diameter $\left(D_{\mathrm{h}}\right)$ of 5 to $22 \mathrm{~nm}$, depending on the VAc content, and a minor population of larger aggregates of $D_{\mathrm{h}} \sim 200 \mathrm{~nm}$ (slow mode of relaxation). It would be tempting to assign the slow mode of relaxation to aggregates in equilibrium with the unimers. However, the weight concentration of these large aggregates is negligible given that the scattered light intensity of these aggregates varies only between 30 and $50 \%$. Indeed, the scattered light intensity being proportional to both $M_{\mathrm{w}}$ and the square of the scatter dimension $\left(R_{\mathrm{g}}{ }^{2}\right)$, the contribution of large aggregates predominates even at very low fraction. ${ }^{53}$ Similar populations of large aggregates were reported for poly(ethylene oxide) (PEO) end-capped with dodecyl groups and were identified as spurious aggregates. ${ }^{53}$ For P(VAc-co-VCL) amphiphilic copolymers with low VAc content $\left(F_{\mathrm{VAc}}<0.3\right)$, the fast mode of relaxation corresponds to a value of the apparent $D_{\mathrm{h}}$ below $7 \mathrm{~nm}$. This suggests that the polymers are present as free polymer chains, which is confirmed by an aggregation number of unity measured by SLS (Table 3). Note that the light scattered by the minor larger aggregates was accounted in order to accurately determine the absolute weight average molar mass $\left(M_{\mathrm{w}}\right)$ and aggregation number of the fast mode of relaxation (see experimental section). For higher content of VAc $\left(F_{\mathrm{VAc}}=0.53\right)$, self-assembly of the P(VAc-co-VCL) copolymer into aggregates of three polymer chains $\left(N_{\mathrm{agg}}=3\right.$, see Table 3) was achieved. The hydrodynamic diameter of the aggregates, measured from the fast mode of relaxation in DLS, was indeed larger $\left(D_{\mathrm{h}} \sim 20 \mathrm{~nm}\right)$. The steeper angular dependence of the light scattered by the $\mathrm{P}\left(\mathrm{VAc}_{0.53}-\mathrm{co}_{-} \mathrm{VCL}_{0.47}\right)$ in comparison with the copolymers with lower VAc content depicts the presence of aggregates for the more hydrophobic copolymer (Figure S.2. in Supporting Information). These results show that a level of $c a 50$ mol-\% of VAc is required to induce non-covalent intermolecular hydrophobic interactions at temperature below the could point, leading to supramolecular assembly. 


\section{CONCLUSION}

In summary, the copolymerization of $N$-vinylcaprolactam with the hydrophobic vinyl acetate is successfully controlled by RAFT polymerization mediated by the $O$-ethyl-S-(1ethoxycarbonyl)ethyldithiocarbonate chain transfer agent to provide a series of well-defined thermoresponsive poly $(N$-vinylcaprolactam-co-vinyl acetate) copolymers with tunable phase transition temperatures and glass transition temperatures. Regardless the initial monomer feed ratio, the synthesis of statistical copolymers fulfills the features of a controlled polymerization with a linear increase of the molar masses and low dispersity values $(\nexists<1.3)$. It should be mentioned that the polymerization control is enhanced by increasing the initial VAc feed ratio. We applied both conventional linearization methods and nonlinear least square methods to estimate reliable values of reactivity ratios for VAc and VCL radical polymerization in regards to the disparate values previously reported in the literature. The nonlinear least squares (NLLS) method based on the integrated form of the copolymerization equation (Skeist equation) provides values of reactivity ratios of $r_{\mathrm{VAc}}=0.33$ and $r_{\mathrm{VCL}}=0.29$ with the azeotropic composition calculated at $f_{\mathrm{VAc}, 0}=0.57$. It should be mentioned that the reactivity ratio values calculated either from linearization techniques such as Kelen-Tüdos, extended Kelen-Tüdos or from nonlinear least-squares fitting, based on the Mayo-Lewis equation at low conversion, fall on the outside limit of the $95 \%$ joint confidence region $\left(0.24<r_{\mathrm{VAc}}<0.45 ; 0.15<r_{\mathrm{VCL}}<0.49\right)$. These results are important to provide information on the copolymer microstructure and clearly indicate a limited monomer compositional drift in the synthesized P(VAc-co-VCL) copolymers. Given the nearly constant composition in VAc and VCL along the polymer chains, the ${ }^{13} \mathrm{C}$ NMR signal of the PVAc methine group is thus influenced by the monomer fraction and the values of the copolymer glass transition $\left(T_{\mathrm{g}}\right)$ are in accordance with the theoretical $T_{\mathrm{g}}$ of statistical copolymers calculated on the basis of the Fox-Flory law. Turbidimetry analyses of the aqueous solutions of the amphiphilic P(VAc-co-VCL) copolymers indicated that the copolymer composition fine tunes the cloud point temperature $\left(T_{\mathrm{cp}}\right)$ between 20 and $30{ }^{\circ} \mathrm{C}$. A linear decrease of the cloud point temperature of the aqueous copolymer solution was observed with the increase of VAc molar fraction in the copolymer. It worth emphasizing that a sharp and reversible temperature phase transition was observed for VCL-rich copolymers while a broadening of this transition occurred for the more hydrophobic $\mathrm{P}\left(\mathrm{VAc}_{0.53}-c o-\mathrm{VCL}_{0.47}\right)$. Interestingly, the P(VAc-co-VCL) copolymers with VAc composition below 30 mol-\% forms unimers in water below $T_{\mathrm{cp}}$, as judged by static light scattering measurements $\left(N_{\mathrm{agg}}=1\right)$ and 
dynamic light scattering $\left(D_{\mathrm{h}} \sim 7 \mathrm{~nm}\right)$. Increasing the VAc content up to 53 mol-\% is sufficient to induce $\mathrm{P}\left(\mathrm{VAc}_{0.53}-\mathrm{co}-\mathrm{VCL}_{0.47}\right)$ copolymer self-assembly into small aggregates $\left(N_{\mathrm{agg}}=3, D_{\mathrm{h}}\right.$ $\sim 20 \mathrm{~nm}$ ) via intermolecular hydrophobic interactions at $10{ }^{\circ} \mathrm{C}\left(T<T_{\mathrm{cp}}\right)$. The knowledge of the minimum hydrophobic fraction resulting in association of $\mathrm{P}(\mathrm{VAc}-\mathrm{co}-\mathrm{VCL})$ chains at room temperature opens perspectives towards the formation of thermoresponsive supramolecular structures such as physically crosslinked colloidal particles synthesized by polymerization induced copolymer self-assembly in aqueous dispersed media. ${ }^{70}$

\section{ACKNOWLEDGEMENTS}

The French ministery of research and the University of Pau and Pays de l'Adour are acknowledged for funding L.E PhD under co-tutella regime with UPV. CNRS is acknowledged for M.S. and S.H. funding. S.H. acknowledges funding from the Agence National de Recherche (Project ASYMCOPO, ANR-15-CE08-0039). The authors are grateful to A. Khoukh for his support to NMR technique.

\section{ASSOCIATED CONTENT}

Supporting Information

The Supporting Information is available as separate file.

\section{AUTHOR INFORMATION}

Corresponding Author

*E-mail: maud.save@univ-pau.fr (M.S.).

Notes

The authors declare no competing financial interest.

\section{REFERENCES}

(1) Roy, D.; Brooks, W. L.; Sumerlin, B. S. New directions in thermoresponsive polymers. Chem. Soc. Rev. 2013, 42, 7214-43.

(2) Vancoillie, G.; Frank, D.; Hoogenboom, R. Thermoresponsive poly(oligo ethylene glycol acrylates). Prog. Polym. Sci. 2014, 39, 1074-1095.

(3) Ramos, J.; Imaz, A.; Forcada, J. Temperature-sensitive nanogels: poly(Nvinylcaprolactam) versus poly(N-isopropylacrylamide). Polym. Chem. 2012, 3, 852-856.

(4) Liu, J.; Debuigne, A.; Detrembleur, C.; Jerome, C. Poly(N-vinylcaprolactam): a thermoresponsive macromolecule with promising future in biomedical field. Advanced healthcare materials 2014, 3, 1941-68.

(5) Cortez-Lemus, N. A.; Licea-Claverie, A. Poly(N-vinylcaprolactam), a comprehensive review on a thermoresponsive polymer becoming popular. Prog. Polym. Sci. 2016, 53, 1-51.

(6) Vihola, H.; Laukkanen, A.; Valtola, L.; Tenhu, H.; Hirvonen, J. Cytotoxicity of thermosensitive polymers poly(N-isopropylacrylamide), poly(N-vinylcaprolactam) and amphiphilically modified poly(N-vinylcaprolactam). Biomaterials 2005, 26, 3055-64.

(7) Liu, J.; Detrembleur, C.; De Pauw-Gillet, M.-C.; Mornet, S.; Duguet, E.; Jérôme, C. Gold nanorods coated with a thermo-responsive poly(ethylene glycol)-b-poly(Nvinylcaprolactam) corona as drug delivery systems for remotely near infrared-triggered release. Polym. Chem. 2014, 5, 799-813. 
(8) Tager, A. A.; Safronov, A. P.; Sharina, S. V.; Galaev, I. Y. Thermodynamic study of poly(n-vinyl caprolactam) hydration at temperatures close to lower critical solution temperature. Colloid and Polymer Science 1993, 271, 868-872.

(9) Beija, M.; Marty, J. D.; Destarac, M. Thermoresponsive poly(N-vinyl caprolactam)coated gold nanoparticles: sharp reversible response and easy tunability. Chem. Commun. 2011, 47, 2826-8.

(10) Peng, H.; Kather, M.; Rübsam, K.; Jakob, F.; Schwaneberg, U.; Pich, A. Water-Soluble Reactive Copolymers Based on Cyclic N-Vinylamides with Succinimide Side Groups for Bioconjugation with Proteins. Macromolecules 2015, 48, 4256-4268.

(11) Peng, H.; Xua, W.; Pich, A. Temperature and $\mathrm{pH}$ dual-responsive poly(vinyl lactam) copolymers functionalized with amine side groups via RAFT polymerization. Polym. Chem. 2016, 7, 5011-5022.

(12) Zhao, X.; Coutelier, O.; Nguyen, H. H.; Delmas, C.; Destarac, M.; Marty, J.-D. Effect of copolymer composition of RAFT/MADIX-derived N-vinylcaprolactam/N-vinylpyrrolidone statistical copolymers on their thermoresponsive behavior and hydrogel properties. Polym. Chem. 2015, 6, 5233-5243.

(13) Kermagoret, A.; Fustin, C.-A.; Bourguignon, M.; Detrembleur, C.; Jérôme, C.; Debuigne, A. One-pot controlled synthesis of double thermoresponsive N-vinylcaprolactambased copolymers with tunable LCSTs. Polym. Chem. 2013, 4, 2575.

(14) Harrisson, S.; Liu, X.; Ollagnier, J.-N.; Coutelier, O.; Marty, J.-D.; Destarac, M. RAFT Polymerization of Vinyl Esters: Synthesis and Applications. Polymers 2014, 6, 1437-1488.

(15) Amann, M.; Minge, O., Biodegradability of Poly(vinyl acetate) and Related Polymers. In Synthetic Biodegradable Polymers, Rieger, B.; Kunkel, A.; Coates, G. W.; Reichardt, R.; Dinjus, E.; Zevaco, T. A., Eds. Springer-Verlag Berlin: Berlin, 2012; Vol. 245, pp 137-172.

(16) Sionkowska, A. Current research on the blends of natural and synthetic polymers as new biomaterials: Review. Prog. Polym. Sci. 2011, 36, 1254-1276.

(17) Jenkins, A. D.; Jones, R. G.; Moad, G. Terminology for reversible-deactivation radical polymerization previously called "controlled" radical or "living" radical polymerization (IUPAC Recommendations 2010). Pure Appl. Chem. 2009, 82.

(18) Braunecker, W. A.; Matyjaszewski, K. Controlled/living radical polymerization: Features, developments, and perspectives. Prog. Polym. Sci. 2007, 32, 93-146.

(19) Nicolas, J.; Guillaneuf, Y.; Lefay, C.; Bertin, D.; Gigmes, D.; Charleux, B. Nitroxidemediated polymerization. Prog. Polym. Sci. 2013, 38, 63-235.

(20) Matyjaszewski, K. Atom Transfer Radical Polymerization (ATRP): Current Status and Future Perspectives. Macromolecules 2012, 45, 4015-4039.

(21) Wang, Y.; Zhong, M.; Zhu, W.; Peng, C.-H.; Zhang, Y.; Konkolewicz, D.; Bortolamei, N.; Isse, A. A.; Gennaro, A.; Matyjaszewski, K. Reversible-Deactivation Radical Polymerization in the Presence of Metallic Copper. Comproportionation-Disproportionation Equilibria and Kinetics. Macromolecules 2013, 46, 3793-3802.

(22) Konkolewicz, D.; Wang, Y.; Krys, P.; Zhong, M.; Isse, A. A.; Gennaro, A.; Matyjaszewski, K. SARA ATRP or SET-LRP. End of controversy? Polym. Chem. 2014, 5, 4409.

(23) Chiefari, J.; Mayadunne, R. T. A.; Moad, C. L.; Moad, G.; Rizzardo, E.; Postma, A.; Thang, S. H. Thiocarbonylthio Compounds ( $\mathrm{SC}(\mathrm{Z}) \mathrm{S}-\mathrm{R})$ in Free Radical Polymerization with Reversible Addition-Fragmentation Chain Transfer (RAFT Polymerization). Effect of the Activating Group Z. Macromolecules 2003, 36, 2273-2283.

(24) Chong, Y. K.; Krstina, J.; Le, T. P. T.; Moad, G.; Postma, A.; Rizzardo, E.; Thang, S. H. Thiocarbonylthio Compounds [SC(Ph)S-R] in Free Radical Polymerization with Reversible Addition-Fragmentation Chain Transfer (RAFT Polymerization). Role of the Free-Radical Leaving Group (R). Macromolecules 2003, 36, 2256-2272. 
(25) Destarac, M.; Bzducha, W.; Taton, D.; Gauthier-Gillaizeau, I.; Zard, S. Z. Xanthates as Chain-Transfer Agents in Controlled Radical Polymerization (MADIX): Structural Effect of the O-Alkyl Group. Macromol. Rapid Commun. 2002, 23, 1049-1054.

(26) Boyer, C.; Lacroix-Desmazes, P.; Robin, J.-J.; Boutevin, B. Reverse Iodine Transfer Polymerization (RITP) of Methyl Methacrylate. Macromolecules 2006, 39, 4044-4053.

(27) Allan, L. E. N.; Perry, M. R.; Shaver, M. P. Organometallic mediated radical polymerization. Prog. Polym. Sci. 2012, 37, 127-156.

(28) Stenzel, M. H.; Cummins, L.; Roberts, G. E.; Davis, T. P.; Vana, P.; Barner-Kowollik, C. Xanthate Mediated Living Polymerization of Vinyl Acetate: A Systematic Variation in MADIX/RAFT Agent Structure. Macromol. Chem. Phys. 2003, 204, 1160-1168.

(29) Favier, A.; Barner-Kowollik, C.; Davis, T. P.; Stenzel, M. H. A Detailed On-Line FT/NIR and 1H NMR Spectroscopic Investigation into Factors Causing Inhibition in XanthateMediated Vinyl Acetate Polymerization. Macromol. Chem. Phys. 2004, 205, 925-936.

(30) Wan, D.; Zhou, Q.; Pu, H.; Yang, G. Controlled radical polymerization ofNvinylcaprolactam mediated by xanthate or dithiocarbamate. J. Polym. Sci., Part A: Polym. Chem. 2008, 46, 3756-3765.

(31) Shao, L.; Hu, M.; Chen, L.; Xu, L.; Bi, Y. RAFT polymerization of N-vinylcaprolactam and effects of the end group on the thermal response of poly(N-vinylcaprolactam). React. Funct. Polym. 2012, 72, 407-413.

(32) Guinaudeau, A.; Coutelier, O.; Sandeau, A.; Mazières, S.; Nguyen Thi, H. D.; Le Drogo, V.; Wilson, D. J.; Destarac, M. Facile Access to Poly(N-vinylpyrrolidone)-Based Double Hydrophilic Block Copolymers by Aqueous Ambient RAFT/MADIX Polymerization. Macromolecules 2014, 47, 41-50.

(33) Shanmugam, S.; Xu, J.; Boyer, C. Photoinduced Electron Transfer-Reversible Addition-Fragmentation Chain Transfer (PET-RAFT) Polymerization of Vinyl Acetate andNVinylpyrrolidinone: Kinetic and Oxygen Tolerance Study. Macromolecules 2014, 47, 49304942.

(34) Girard, E.; Liu, X.; Marty, J.-D.; Destarac, M. RAFT/MADIX (co)polymerization of vinyl trifluoroacetate: a means to many ends. Polym. Chem. 2014, 5, 1013-1022.

(35) Debuigne, A.; Caille, J.-R.; Jérôme, R. Synthesis of End-Functional Poly(vinyl acetate) by Cobalt-Mediated Radical Polymerization. Macromolecules 2005, 38, 5452-5458.

(36) Miao, X.; Zhu, W.; Zhang, Z.; Zhang, W.; Zhu, X.; Zhu, J. Photo-induced cobaltmediated radical polymerization of vinyl acetate. Polym. Chem. 2014, 5, 551-557.

(37) Kermagoret, A.; Mathieu, K.; Thomassin, J.-M.; Fustin, C.-A.; Duchêne, R.; Jérôme, C.; Detrembleur, C.; Debuigne, A. Double thermoresponsive di- and triblock copolymers based on N-vinylcaprolactam and $\mathrm{N}$-vinylpyrrolidone: synthesis and comparative study of solution behaviour. Polym. Chem. 2014, 5, 6534-6544.

(38) Tonnar, J.; Pouget, E.; Lacroix-Desmazes, P.; Boutevin, B. Synthesis of poly(vinyl acetate)-b-poly(dimethylsiloxane)-b-poly(vinyl acetate) triblock copolymers by iodine transfer polymerization. European Polymer Journal 2008, 44, 318-328.

(39) Jiang, X.; Li, Y.; Lu, G.; Huang, X. A novel poly(N-vinylcaprolactam)-based welldefined amphiphilic graft copolymer synthesized by successive RAFT and ATRP. Polym. Chem. 2013, 4, 1402-1411.

(40) Yang, Y.; Tang, G.; Hu, M.; Shao, L.; Li, J.; Bi, Y. High-efficiency synthesis of welldefined cyclic poly(N-vinylcaprolactam) and its solution properties. Polymer 2015, 68, 213220.

(41) Liang, X.; Kozlovskaya, V.; Cox, C. P.; Wang, Y.; Saeed, M.; Kharlampieva, E. Synthesis and self-assembly of thermosensitive double-hydrophilic poly(N-vinylcaprolactam)b-poly(N-vinyl-2-pyrrolidone) diblock copolymers. J. Polym. Sci., Part A: Polym. Chem. 2014, 52, 2725-2737. 
(42) Maji, S.; Zhang, Z.; Voorhaar, L.; Pieters, S.; Stubbe, B.; Van Vlierberghe, S.; Dubruel, P.; De Geest, B. G.; Hoogenboom, R. Thermoresponsive polymer coated gold nanoparticles: from MADIX/RAFT copolymerization of $\mathrm{N}$-vinylpyrrolidone and $\mathrm{N}$-vinylcaprolactam to salt and temperature induced nanoparticle aggregation. RSC Adv. 2015, 5, 42388-42398.

(43) Bendejacq, D. D.; Ponsinet, V. Double-polyelectrolyte, like-charged amphiphilic diblock copolymers: Swollen structures and $\mathrm{pH}$ - and salt-dependent lyotropic behavior. J. Phys. Chem. B 2008, 112, 7996-8009.

(44) Lejeune, E.; Drechsler, M.; Jestin, J.; Mueller, A. H. E.; Chassenieux, C.; Colombani, O. Amphiphilic Diblock Copolymers with a Moderately Hydrophobic Block: Toward Dynamic Micelles. Macromolecules 2010, 43, 2667-2671.

(45) Moskowitz, J. D.; Wiggins, J. S. Semibatch RAFT copolymerization of acrylonitrile and $\mathrm{N}$-isopropylacrylamide: Effect of comonomer distribution on cyclization and thermal stability. Polymer 2016, 84, 311-318.

(46) Charbonneau, C.; Chassenieux, C.; Colombani, O.; Nicolai, T. Controlling the Dynamics of Self-Assembled Triblock Copolymer Networks via the $\mathrm{pH}$. Macromolecules 2011, 44, 4487-4495.

(47) Cherifi, N.; Issoulie, A.; Khoukh, A.; Benaboura, A.; Save, M.; Derail, C.; Billon, L. Synthetic methodology effect on the microstructure and thermal properties of poly(n-butyl acrylate-co-methyl methacrylate) synthesized by nitroxide mediated polymerization. Polym. Chem. 2011, 2, 1769.

(48) Mok, M. M.; Pujari, S.; Burghardt, W. R.; Dettmer, C. M.; Nguyen, S. T.; Ellison, C. J.; Torkelson, J. M. Microphase separation and shear alignment of gradient copolymers: Melt rheology and small-angle X-ray scattering analysis. Macromolecules 2008, 41, 5818-5829.

(49) Kirsh, Y. E., Water Soluble Poly-N-Vinylamides: Synthesis and Physicochemical Properties. Chichester: Johm Wiley and Sons, Inc;: 1998.

(50) Pashkin, II; Kirsh, Y. E.; Zubov, V. P.; Anisimova, T. V.; Kuzkina, I. F.; Voloshina, Y. P.; Krylov, A. V. Synthesis of water-soluble n-vinyl caprolactam-based copolymers and physicochemical properties of their aqueous-solutions. Vysokomol. Soedin. 1993, 35, A481A484.

(51) Brandrup, J.; Immergut, E. H.; Grulke, E. A., Polymer Hanbook, 4th Edition. 2003; p 2336.

(52) Bernard, J.; Favier, A.; Zhang, L.; Nilasaroya, A.; Davis, T. P.; Barner-Kowollik, C.; Stenzel, M. H. Poly(vinyl ester) Star Polymers via Xanthate-Mediated Living Radical Polymerization: From Poly(vinyl alcohol) to Glycopolymer Stars. Macromolecules 2005, 38, 5475-5484.

(53) Chassenieux, C.; Nicolai, T.; Durand, D. Association of Hydrophobically End-Capped Poly(ethylene oxide). Macromolecules 1997, 30, 4952-4958.

(54) Lejeune, E.; Chassenieux, C.; Colombani, O., pH Induced Desaggregation Of Highly Hydrophilic Amphiphilic Diblock Copolymers. In Trends in Colloid and Interface Science Xxiv, Starov, V.; Prochazka, K., Eds. 2011; Vol. 138, pp 7-16.

(55) Patterson, J. P.; Kelley, E. G.; Murphy, R. P.; Moughton, A. O.; Robin, M. P.; Lu, A.; Colombani, O.; Chassenieux, C.; Cheung, D.; Sullivan, M. O.; Epps, T. H., III; O'Reilly, R. K. Structural Characterization of Amphiphilic Homopolymer Micelles Using Light Scattering, SANS, and Cryo-TEM. Macromolecules 2013, 46, 6319-6325.

(56) Dufils, P. E.; David, G.; Boutevin, B.; Woodward, G.; Otter, G.; Guinaudeau, A.; Mazières, S.; Destarac, M. Phosphonate-terminated poly(vinyl acetate) synthesized by RAFT/MADIX polymerization. J. Polym. Sci., Part A: Polym. Chem. 2012, 50, 1997-2007.

(57) Mayo, F. R.; Lewis, F. M. Copolymerization I : A basis for comparing the behavior of monomers in copolymerization, the copolymerization of styrene and methyl methacrylate. Macromolecules 1944, 66, 1594-1601. 
(58) Kelen, T.; Tüdos, F. Analysis of linear methods for determining copolymerization reactivity ratios .1. New improved linear graphic method. J. Macromol. Sci. Chem. 1975, A9, $1-27$.

(59) Tüdos, F.; Kelen, T.; Földes-Berezsnich, T.; Turcsanyi, B. Analysis of linear methods for determining copolymerization reactivity ratios. III. Linear graphic method for evaluating data obtained at high conversion levels. Journal of Macromolecular Science-Chemistry 1976, $10,1513-1540$.

(60) Hunley, M. T.; Beers, K. L. Nonlinear Method for Determining Reactivity Ratios of Ring-Opening Copolymerizations. Macromolecules 2013, 46, 1393-1399.

(61) Van Den Brink, M.; Van Herk, A. M.; German, A. L. Nonlinear regression by visualization of the sum of residual space applied to the integrated copolymerization equation with errors in all variables. I. Introduction of the model, simulations and design of experiments. J. Polym. Sci., Part A: Polym. Chem. 1999, 37, 3793-3803.

(62) Lessard, B. t.; Schmidt, S. C.; Marić, M. Styrene/Acrylic Acid Random Copolymers Synthesized by Nitroxide-Mediated Polymerization: Effect of Free Nitroxide on Kinetics and Copolymer Composition. Macromolecules 2008, 41, 3446-3454.

(63) Guerrero-Sanchez, C.; Harrisson, S.; Keddie, D. J. High-Throughput Method for RAFT Kinetic Investigations and Estimation of Reactivity Ratios in Copolymerization Systems. Macromol. Symp. 2013, 325-326, 38-46.

(64) Skeist, I. Copolymerization: the Composition Distribution Curve. J. Am. Chem. Soc. 1946, 68, 1781-1784.

(65) Meyer, V. E.; Lowry, G. G. Integral and differential binary copolymerization equations. Journal of Polymer Science Part A: General Papers 1965, 3, 2843-2851.

(66) Harrisson, S.; Ercole, F.; Muir, B. W. Living spontaneous gradient copolymers of acrylic acid and styrene: one-pot synthesis of pH-responsive amphiphiles. Polym. Chem. 2010, 1, 326-332.

(67) Klumperman, B.; Chambard, G.; Brinkhuis, R. H. G., Peculiarities in atom transfer radical copolymerization. In Advances in Controlled/Living Radical Polymerization, Matyjaszewski, K., Ed. 2003; Vol. 854, pp 180-192.

(68) Zapata-Gonzalez, I.; Hutchinson, R. A.; Matyjaszewski, K.; Saldivar-Guerra, E.; OrtizCisneros, J. Copolymer Composition Deviations from Mayo-Lewis Conventional Free Radical Behavior in Nitroxide Mediated Copolymerization. Macromol. Theory Simul. 2014, 23, 245265.

(69) Kirsh, Y. E.; Yanul, N. A.; Kalninsh, K. K. Structural transformations and water associate interactions in poly-N-vinylcaprolactam-water system. European Polymer Journal 1999, 35, 305-316.

(70) Delaittre, G.; Save, M.; Gaborieau, M.; Castignolles, P.; Rieger, J.; Charleux, B. Synthesis by nitroxide-mediated aqueous dispersion polymerization, characterization, and physical core-crosslinking of $\mathrm{pH}$ - and thermoresponsive dynamic diblock copolymer micelles. Polym. Chem. 2012, 3, 1526. 


\section{TOC Graphic for}

RAFT copolymerization of vinyl acetate and $N$-vinylcaprolactam: kinetics, control, copolymer composition and thermoresponsive self-assembly

Laura Etchenausia, ${ }^{1}$ Aurélie Malho Rodrigues, ${ }^{1}$ Simon Harrisson, ${ }^{2}$ Elise Deniau-Lejeune, ${ }^{1}$ Maud Save ${ }^{1 *}$

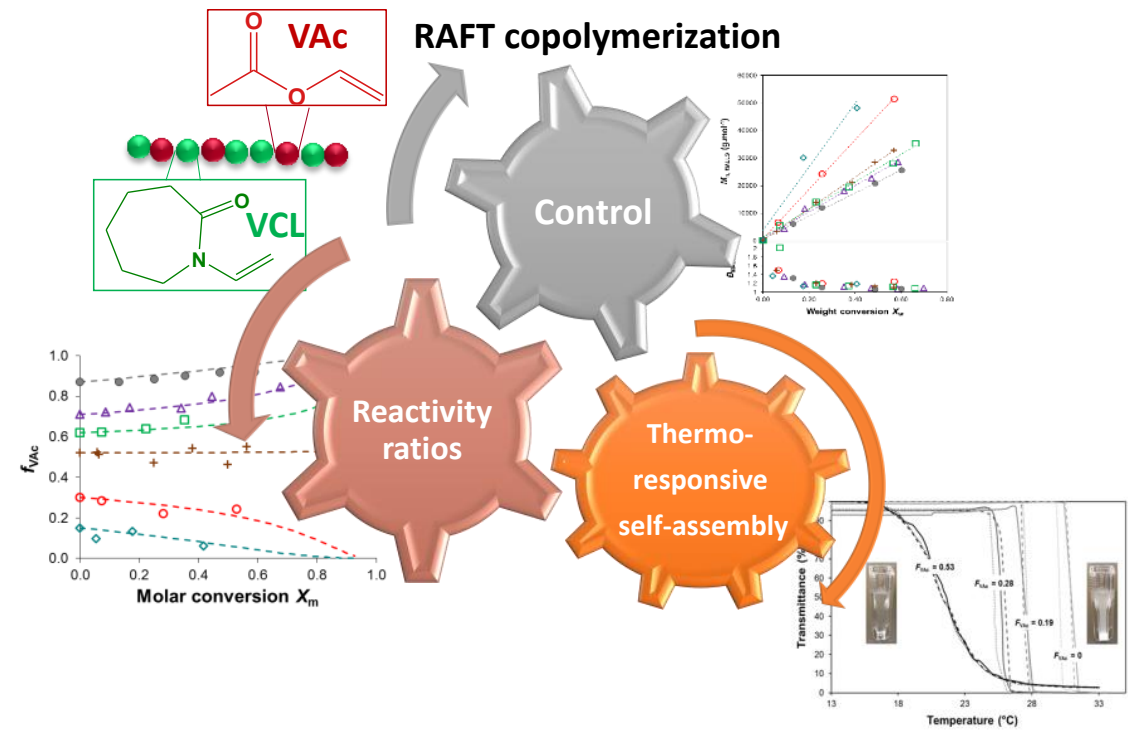

